\title{
Center for Electronics and Electrical Engineering
}

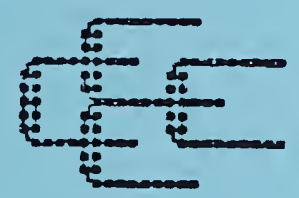

Technical

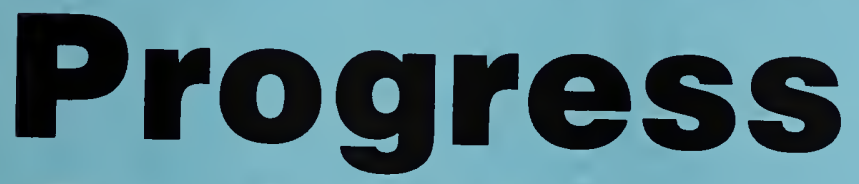

Bulletin

Covering Center Programs, October to December 1987 with 1988 CEEE Events Calendar

June 1988

U.S. Department of Commerce National Bureau of Standards National Engineering Laboratory Gaithersburg, Maryland 20899
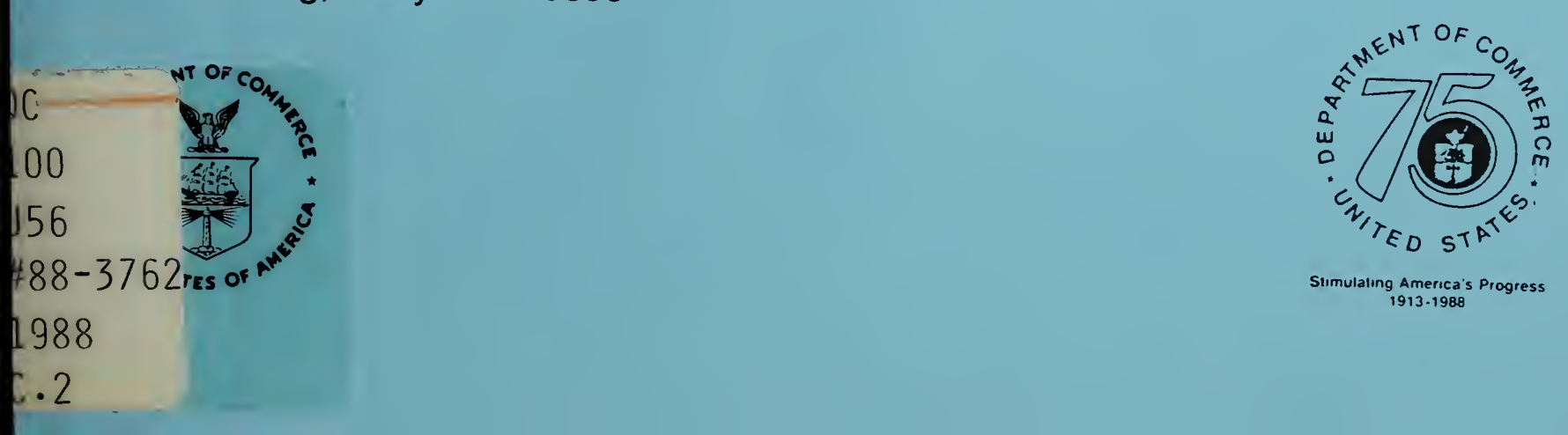
This is the twenty-first issue of a quarterly publication providing information on the technical work of the National Bureau of Standards Center for Electronics and Electrical Engineering. This issue of the CEEE Technical Progress Bulletin covers the fourth quarter of calendar year 1987.

Organization of Bulletin: This issue contains abstracts for all Center papers released for publication by NBS in the guarter and citations and abstracts for Center papers published in the quarter. Entries are arranged by technical topic as identified in the table of contents and alphabetically by first author under each subheading within each topic. Unpublished papers appear under the subheading "Released for Publication". Papers published in the guarter appear under the subheading "Recently Published". Following each abstract is the name and telephone number of the individual to contact for more information on the topic (usually the first author). This issue also includes a calendar of Center conferences and workshops planner for calendar year 1988 and a list of sponsors of the work.

Center for Electronics and Electrical Engineering: Center proqrams provide national reference standards, measurement methods, supporting theory and data, and traceability to national standards.

The metrological products of these programs aid economic growth by promoting equity and efficiency in the marketplace, by removing metrological barriers to improved productivity and innovation, by increasing U. S. competitiveness in international markets through facilitation of compliance with international agreements, and by providing technical bases for the development of voluntary standards for domestic and international trade. These metrological products also aid in the development of rational regulatory policy and promote efficient functioning of technical programs of the Government.

The work of the Center is divided into two major programs: the Semiconductor Technology Program, carried out by the Semiconductor Electronics Division in Gaithersburg, MD, and the Signals and Systems Metrology Program, carried out by the Electrosystems Division in Gaithersburg and the Electromagnetic Fields and Electromagnetic Technology Divisions in Boulder, CO. Key contacts in the center are given on the back cover; readers are encouraged to contact any of these individuals for further information. To request a subscription or for more information on the Bulletin, write to CEEE Technical Progress Bulletin, National Bureau of Standards, $\overline{\text { Metrology }}$ Building, Room B-358, Gaithersburg, MD 20899 or call (301) 975-2220.

Center sponsors: The Center Programs are sponsored by the National Bureau of Standards and a number of other organizations, in both the Federal and private sectors; these are identified on page 35.

Note on Publication Lists: Guides to earlier as well as recent work are the publication lists covering the work of each division. These lists are revised and reissued on an approximately annual basis and are available from the originating division. The current set is identified in the Additional Information section, paqe 34. 
Device Physics and Modeling. Radiation Effects.

Insulators and Interfaces Photodiodes.

Other Semiconductor Metrology Topics

FAST SIGNAL ACQUISITION, PROCESSING, \& TRANSMISSION

Waveform Metrology

Cryoelectronic Metrology

Antenna Metrology .

Laser Metrology

Noise Metrology

Microwave and Millimeter-Wave Metrology

Optical Fiber Metrology

Electro-Optic Metrology

Other Fast Signal Topics

ELECTRICAL SYSTEMS

Power Systems Metrology .

Superconductors

Magnetic Materials and Measurements

ELECTROMAGNETIC INTERFERENCE •

Radiated Electromagnetic Interference

Conducted Electromagnetic Interference ADDITIONAL INFORMATION • 1988 CEEE CALENDAR 


\section{SEMICONDUCTOR TECHNOLOGY}

Silicon Materials

Recently Published

Carver, G.P., Kang, S.S., Ehrstein, J.R., and Novotny, D.B., Well-Defined Contacts Produce Accurate Spreading Resistance Measurements, Journal of the Electrochemical Society, Vol. 134, No. 11, pp. 2878-2882 (November 1987).

Values of silicon resistivity calculated from spreading resistance measurements agree with values of resistivity determined from four-point probe measurements over a range of dopant density from $9 \times$ $10^{14}$ to $2 \times 10^{17} \mathrm{~cm}^{-3}$. The spreading resistance resistivity values were determined solely using a mathematical expression based upon a simple geometrical model, without the need for a separate calibration. The measurements were made using aluminum-silicon contacts having a well-defined geometry. Arrays of such contacts were also used to characterize local resistivity variations. Two-contact spreading resistance measurements are shown to underestimate the amplitude of resistivity variations compared to one-contact measurements.

[Contact: Gary P. Carver, (301)

975-2091]

Polak-Dingels, P. , Burdge, G., Lee, Chi H., Seabaugh, A.C., Brundage, R.T., Bell, M.I., and Albers, J., An Investigation of Photoconductive Picosecond Microstripline switches on selfImplanted Silicon on Sapphire (SOS), Picosecond Electronics and Optoelectronics II, F.J. Leonberger, C.H. Lee, F. Capasso, and H. Morkoc, Eds. (Springer-Verlag, 1987), pp. 232-236. [Conference proceedings of the $2 d$ Topical Meeting on Picosecond Electronics and optoelectronics, Incline Village, Nevada, January 14-16, 1987 ]

Silicon-on-sapphire (sos) switches, damaged by implantation with $270-\mathrm{keV}$ si ions at fluence levels of 1012 to $2 \times$
$10^{15} \mathrm{~cm}^{-2}$, have been characterized hy picosecond cross-correlation, Raman, and resistivity measurements. Response times as short as 9 ps were measured for an implant dose of $10^{14}$. Raman measurements indicate amorphous silicon is not formed until the dose reaches $2 \times 10^{15}$ $\mathrm{cm}^{-2}$, but there is no further decrease in response time at the higher doses. The resistivity peaks at the same dose level at which the minimum response time is observed, and then decreases for higher dose. The mobility decreases monotonically with increasing implant dose. We find the optimum implantation condition is one that produces heavy damage in the material without fully amorphizing the silicon. Amorphization decreases the on/off ratio of the device through reduction of both dark resistance and mobility, without increasing the speed of the device.

[Contact: Michael I. Bell, (301)

975-2044]

\section{Gallium Arsenide Materials}

Released for Publication

Lowney, J.R., and Kahn, A.H., ValenceBand Effective Masses of GaAs.

The density of states effective masses for the heavy-hole, light-hole, and split-off valence bands of GaAs have been calculated as a function of energy in each band. The calculations are based on the theory of Dresselhaus, Kip, and Kittel with matrix elements determined by the method of cardona. The most recent values for these matrix elements are used. Provision has heen made for the effect of the split-off energy on the matrix elements of the split-off band. The results show important nonparabolicities which should be taken into account in modeling the valence band.

[Contact: Jeremiah R. Jowney, (301) 975-2048]

Recently Published

Forman, R.A., Hill, J.R., Bell, M.I., 
Gallium Arsenide Materials (cont'd.)

White, G.S., Freiman, S.W., and Ford, W. Strain Patterns in Gallium Arsenide Wafers: Origins and Effects, Proceedings of the International Symposium on Defect Recognition and Image Processing in III-V Compounds (DRIP 1987), Monterey, California, April 27-29, 1987, E.R. Weber, Ed. (Elsevier Science Publishers B.V., Amsterdam, 1987), pp. 63-71.

Using the rapid $\mathrm{x}$-ray topographic system described earlier (in the Proceedings of DRIP I), we have examined a large number of LEC GaAs wafers, both commercial and research, and have been able to identify the sources of some of the observed patterns. We have also studied the effects of the inhomogeneous strain on the fracture properties of the wafers. The high gradients of strain cause deviations from expected crack growth behavior in fracture tests. These deviations include crack velocity variations and crack tip deflections. The grown-in defects cause point-to-point irreproducibility in hardness and toughness values for this material. Sequential wafers exhibit closely related topographs and similar fracture properties. Inclusions have been identified in indium-doped wafers and produce a characteristic topographic pattern when the inclusion lies in the wafer under study. A characteristic strain pattern propagates away from the inclusion and produces annular rings in later wafers. The relaxation of the bow-tie strain pattern surrounding the inclusion to the annular ring pattern is likely related to the thermoelastic stress patterns described by Jordan et al.

[Contact: James R. Hill, (301)

975-2049]

Analysis Techniques

Released for Publication

Jach, T., Novotny, D.B., Carver, G.P., Geist, J., and Spal, R.D., An X-Ray Monochromator Crystal Which Detects the
Bragg Condition, to be published in Nuclear Instrumentation and Methods in Physics Research.

We have fabricated a (111) silicon $x-r a y$ monochromator crystal with a diode diffused into its surface. Without suffering any apparent degradation in its rocking-curve width at the Bragq condition, the crystal provides a dc current which changes dramatically at the diffraction of a monochromatic x-ray heam. The current change is directly attributable to extinction at the Bragg angle. It provides a new means to align the two crystals of a double-crystal x-ray monochromator using a Eeedback circuit.

[Contact: Donald R. Novotny, (301)

975-2699]

\section{Recently Published}

Bouldin, C.E., Forman, R.A., and Re 11, M.I., Silicon photodiode for Fluorescence EXAFS, Review of Scientific Instruments, Vol. 58, No. 10, pp. 1891-1894 (October 1987).

A large-area silicon diode is used as a fluorescence detector for extended $x-r a y$ absorption fine structure (EXAFS) measurements. A direct comparison of this diode detector relative to a gas ionization fluorescence detector is made. Advantages of the diode detector include: higher signal for a qiven photon flux (due to higher quantum efficiency), vacuum and cryoqenic compatibility, freedom from microphonic noise, good linearity, extremely wide dynamic range, operation without hiqh voltage or gas connections, very simple electronics, and low cost. A brief comparison with other detection methods for fluorescence EXAFS is given. Use of photodiodes for transmission EXAFS is discussed.

[Contact: Charles E. Bouldin, (301)

975-2046]

Dimensional Metrology

Recently Published

Galloway, K.F., Diehl, S.E., and Lin- 
Dimensional Metrology (cont'd.)

holm, L.W., Metrological Challenges in Semiconductor Technology: Electrical Measurements of Dimensions and Materials Properties Using Integrated Circuit Test structures, Proceedings of the International conference on Semiconductor \& Integrated Circuit Technology, Beijing, China, October 19-26, 1986, W. Xiuying and $M$. Vangxian, Eds., pp. 685-687 (World Scientific Publishers, PTE Ltd., Singapore, 1986).

The effective characterization and control of the materials, processes, devices, and circuits for very-large-scale integration (VLSI) is a major concern for semiconductor technology development. This paper reviews the types of metrological requirements associated with VLSI semiconductor technology and examines dimensional measurements and materials characterization at the wafer or chip level. Integrated circuit test structures for electrical measurements of dimensions and material properties are described.

[Contact: Loren W. Linholm, (301)

975-2052]

Nyyssonen, D., Computer Software for the Computation of the Scattered Field and the Optical Microscope Image of Line objects Patterned in Thick Layers, NBSIR 87-3618 (December 1987).

This report provides computer software for calculating optical microscope images of line objects patterned in thick layers $(>\lambda / 4$ thick). The algorithms used are based on a monochromatic, waveguide model which can predict the images of line objects with arbitrary edge geometry, including multilayer structures with sloped, curved, asymmetric, and undercut edges. Along with the computer software listing, the mathematics of the model, a short description of its structure and use, and test cases for help in implementation are given.
[Contact: Robert D. Larrabee, (301)

975-2298]

Postek, M.T., Low Accelerating Voltage Pitch Standard Based on the Modification of NBS SRM 484, NBSIR 87-3665 (Oc tober 1987).

The National Bureau of Standards is actively developing micrometer and submicrometer standards for the scanning electron microscope (SEM). This report summarizes the proqress made to extend the imaging range of the presently available SRM 484 for use as an interim standard for low-accelerating-voltage magnification calihration applications for the SEM.

[Contact: Michael T. Postek, (301) 975-2299]

Postek, M.T., Resolution and Measurement in the Scanning Electron Microscope, Proceedings of the 45 th Annual Meeting of the Electron Microscope Society of America, G.W. Bailev, Ed., pp. 534-537 (Oc tober 1987).

The terms ultimate resolution or resolving power refer to the very best performance that can be obtained from a scanning electron microscope (SEM) aiven the optimum instrumental conditions and sample. However, as it relates to SFM users, the conventional definitions of this figure are ambiguous. The numbers quoted for the resolution of an instrument are not only theoretically derived, but are also verified through the direct measurement of images on microqraphs. However, the samples commonly used for this purpose are specifically optimized for the measurement of instrument reso lution and are most often not typical of the sample used in practical applications.

[Contact: Michael T. Postek, (301)

975-2299]

Packaging

Recently Published

Harman, G.G., Acoustic Fmission Test 
Packaging (cont'd.)

for Microelectronic Tape Automated Bonding, Acoustic Emission Thermal Shock Test for Hybrid Microcircuit Packages, and Designing Microelectronic Welds for Acoustic Emission Testability, Parts 4, 5, and 9, Sec. 11, Vol. 5, Second Edition, Nondestructive Testing Handbook, P. McIntire, Ed., pp. 361 et seq. (American Society for Nondestructive Testing, 1987).

In Part 4, an acoustic-emission ( $A E$ ) test method for tape automated bonding ( $T A B)$ integrity is presented, consisting of a precision testing machine that simultaneously applies a clamping force on the semiconductor chip and a lifting force on the electrical interconnecting leads. Acoustic-emission signals are transmitted through a waveguide to the detector. The system also permanently forms (raises) the leads, which is a normal requirement for TAB devices. Large acoustic-emission signals occur when a lead breaks, a bump lifts, or a weld crack propagates. Appropriate AE signal processing is also discussed.

Part 5 describes an acoustic-emissionmonitored test for hybrid microcircuit package integrity which consists of a hot stage operating at $400^{\circ} \mathrm{C}$, a special water-cooled acoustic-emission detector mount, and appropriate signal recording equipment. In use, the detector is coupled to the back of a hybrid package and both are set on the hot stage for approximately $30 \mathrm{~s}$. Any acoustic-emission signals indicate thermal excursion damage to the glass-metal seals. The acoustic-emission signals were correlated with both room-temperature and $125^{\circ} \mathrm{C}$ leak tests of the packages.

Finally, in Part 9, development of tests to detect poor welds in microelectronic components is discussed. Failure modes must be understood, and this is done by understanding the characteristics of unacceptable welds.

[Contact: George G. Harman, (301)

975-2097]
Integrated Circuit Test structures

Released for Publication

Buehler, M.G., Linholm, J.W., Tyree, V.C., Allen, R.A., Blaes, B.R., Hicks, K. A., and Jennings, G. A., Proposed End-of-Fabrication Parametric Test structures for the CHOS Process Monitor, to be published as Jet propulsion Iaboratory Report \#D-4520.

This document describes a proposed endof-fabrication CMOS Process Monitor for VHSIC/VLSI wafer Fabrication oualification. The discussion of the CMOS Process Monitor includes a description of the test structures, test methods, and data analysis techniques needed to acquire 26 key electrical parameters that characterize a CMOs process. This process monitor has heen under development for a number of years at JPL's VLSI Technology Group and the University of Southern California/Information sciences Institute MosIs Project.

[Contact: Loren W. Linholm, (301)

975-2052]

Kim, J.S., Linholm, L.W., Barley, B.I., Hanes, M.H., and Cresswell, M.W., A Microelectronic Test structure for Thickness Determination of Homogeneous Conducting Thin Films in VLSI Processing, to be published in tbe proceedings of the 1988 IEEF Conference on Microelectronic Test Structures, Long Beach, California, February 22-23, 1988.

This paper describes a new test structure for use in determining the thickness of a uniform conducting film. The structure incorporates the van der Pauw cross method to determine the effective sheet resistance of a vertical, uniformly doped cross section of a polysilicon film and a bridge resistor to determine the thickness of the film. Ry using a composite structure, which consists of the vertical cross structure and a conventional planar cross-bridqe test structure, it is possible to obtain the 


\section{IC Test Structures (cont'd.)}

thickness, linewidth, and resistivity of a conducting line.

[Contact: Jin S. Kim, (301) 975-2238]

Linholm, L.W., Khera, D., Reeve, C.P., and Cresswell, M.W., A Developmental Expert System for Test Structure Data Evaluation, to be published in the Proceedings of the 1988 IEEE Conference on Microelectronic Test structures, Long Beach, California, February 22-23, 1988.

This paper describes a developmental expert system, rule generation techniques, a test chip, data handling methods, and statistical data reduction techniques for characterizing the performance of a $1-\mu \mathrm{m}$ lithography process. Examples of test results and an expert system diagnosis are given. [Contact: Loren W. Linholm, (301)

975-2052]

Schafft, H.A., and Albers, J., Thermal Interactions Between Electromigration Test structures, to be published in the proceedings of the 1988 IEEF Conference on Microelectronic Test Structures, Long Beach, California, February 22-23, 1988.

The thermal interaction between electromigration test structures on a test chip, when subjected to a high currentdensity stress, must be considered when making median-time-to-failure measurements.

[Contact: Harry A. Schafft, (301)

975-2234]

Suehle, J.S., and Galloway, K.F., Switching Time Degradation in synchronously stressed Transmission Gates.

When subjected to synchronous timing pulsed stress, the hot-carrier response of n-channel transistors in CMOS and NMOS transmission gates is different. Due to the circuit configuration, hot-carrier-induced charge builds up at both the source and the drain reqions of the n-channel transistor. The charqe is asymetric for the NMOs transmission gate and nearly symetric for the CMOS case. During stress, the growth of the symmetrical charge distribution in the cMos transmission gate becomes self-limiting and suppresses further device degradation.

[Contact: John S. Suehle, (301)

975-2247]

Suehle, J.S., and Galloway, K.F., Test Circuit structures for Characterizing the Effects of Localized Hot-CarrierInduced Charge in VLSI Switching Circuits, to be published in the proceedings of the 1988 IfEE Conference on Microelectronic Test Structures, Lonq Beach, California, February 22-23, 1988.

Data are presented that were collected from test circuit structures that were hot-carrier stressed under conditions existing in actual VLSI switching circuits. It is shown that the localized nature of hot-carrier induced damage to n-channel MOSFETs must he considered to accurately model these data by computer circuit simulations.

[Contact: John S. Suehle, (301)

975-2247]

Recently Published

Galloway, K.F., Diehl, S.E., and Linholm, L.W., Metrological Challenges in Semiconductor Technology: Electrical Measurements of Dimensions and Materials Properties Using Integrated Circuit rest structures, proceedings of the International Conference on semiconductor \& Integrated Circuit Technology, Beijing, China, nctoher 19-26, 1986, W. Xiuyinq and $M$. Vangxian, Eds. (World Scientific Publishers, PTE Ltd., Singapore, 1986), pp. 685-687.

The effective characterization and control of the materials, processes, तevices, and circuits for very-larqe-scale integration (VLSI) is a major concern 
IC Test structures (cont'd.)

for semiconductor technology development. This paper reviews the types of metrological requirements associated with VLSI semiconductor technology and examines dimensional measurements and materials characterization at the wafer or chip level. Integrated circuit test structures for electrical measurements of dimensions and material properties are described.

[Contact: Loren W. Linholm, (301)

975-2052]

Schafft, H.A., Electromigration Guidelines for $t_{50}$ Measurements, Final Report of the 1986 Workshop on Wafer Reliability Assessment, O.D. Trapp, Ed., Lake Tahoe, California, October 19-22, 1986, pp. 149-161 (1987).

Guidelines for designing electromigration test structures and test procedures are proposed. These guidelines are intended to promote the reproducibility of electromigration characterizations of metallizations used in VLSI circuits. [Contact: Harry A. Schafft, (301)

975-2234]

Suehle, J.S., Russell, T.J., and Galloway, K. F., Interface Trap effects on the Hot-Carrier-Induced Degradation of MOSFETs During Dynamic stress, IEEE Transactions on Nuclear Science, Vol. NS-34, No. 6, pp. 1359-1363 (1987) .

Foundry and hardened n-channel MOSFETS were stressed with dynamic AC pulses and with static DC voltages. The pre-radiation hot-carrier-induced degradation is much more severe in the dynamic case than in the static case for the hardened devices. The data suggest that the pre-radiation hot-carrier degradation is strongly influenced by the relative density of interface traps and by the pulse structure. The post-radiation hot-carrier degradation is mainly influenced by the amount of radiation-induced fixed oxide charge.

[Contact: John S. Suehle, (301)

975-2247]
Power Devices

Released for Publication

Blackburn, D.L., A Review of Thermal Characterization of Power Transistors, to be published in the proceedings of the IEEF, Semiconductor Thermal and Temperature Measurement (SFMITHERM) Symposium, San Diego, California, February 10-12, 1988.

The thermal characteristics of power transistors and their measurement are discussed. Topic areas addressed include general methods for measurina device temperature, control of the thermal environment, selection of a temperature-sensitive electrical parameter, measurement of temperature-sensitive electrical parameters, reasons for measuring temperature, and temperature measurement of integrated power devices. procedures for detecting nonthermal switching transients, extrapolation of the measured temperature to the instant of switching, and for measuring the temperature of Darlington transistors are included.

[Contact: David L. Blackhurn, (301)

975-2068]

Hefner, A.R., and Blackburn, D.L., An Analytical Model for the steady-state and Transient Characteristics of the Power Insulated Gate Bipolar Transistor.

An analytical model for the power Insulated Gate Bipolar Transistor (IGBT) is developed. The model predicts the IGBT steady-state current-voltage characteristics and switching transient current and voltage waveforms for all practical loading conditions. The model is based on the equivalent circuit of a MOSFET which supplies the base current to a low-gain, high-level injection, bipolar transistor with its base virtual contact at the collector end of the hase. The basic element of the model is a detailed analysis of the bipolar transistor which uses ambipolar transport theory and does not assume a quasi-static condition for 
Power Devices (cont'd.)

the transient analysis. This analysis differs from the previous bipolar transistor theory in that 1) the relatively large base current which flows from the collector end of the base is properly accounted for, and 2) the component of current due to the changing carrier distribution under the condition of a moving collector-base depletion edge during anode voltage transitions is accounted for. Experimental verification of the model using devices with different base lifetimes is presented for the on-state current-voltage characteristics, the steady-state saturation current, and the current and voltage waveforms for the constant voltage transient, the inductive load transient, and the series resistor-inductor load transient.

[Contact: Allen R. Hefner, (301)

975-2071]

Hefner, A.R., Blackburn, D.L., and Galloway, K.F., A steady-State Model for the Insulated Gate Bipolar Transistor, to be published in the Proceedings of the Fourth International Workshop on Physics of semiconductor Devices, Madras, India, December 10-15, 1987.

The power Insulated Gate Bipolar Transistor (IGBT) is a switching device designed to overcome the high on-state loss of the power MOSFET. The IGBT behaves as a bipolar transistor which is supplied base current by a MOSFET. The bipolar transistor of the IGBT has a wide base with the base contact at the collector edge of the base and is operated with its base in high-level injection. The usual bipolar transistor models are not adequate for the IGBT. This paper describes a model for the IGBT developed using ambipolar transport.

[Contact: Allen R. Hefner, (301)

975-2071]

Device Physics and Modeling
Released for Publication

He fner, A.R., and Blackburn, D.L., An Analytical Model for the Steady-State and Transient Characteristics of the Power Insulated Gate Bipolar Transistor.

An analytical model for the power Insulated Gate Bipolar Transistor (IGBT) is developed. The model predicts the IGBT steady-state current-voltage characteristics and switching transient current and voltage waveforms for all practical loading conditions. The model is based on the equivalent circuit of a MOSFET which supplies the base current to a low-gain, high-level injection, bipolar transistor with its base virtual contact at the collector end of the base. The basic element of the model is a detailed analysis of the bipolar transistor which uses ambipolar transport theory and does not assume a quasi-static condition for the transient analysis. This analysis differs from the previous bipolar transistor theory in that 1) the relatively large base current which flows from the collector end of the base is properly accounted for, and 2) the component of current due to the chanqing carrier distribution under the condition of a moving collector-base depletion edge during anode voltage transitions is accounted for. Experimental verification of the model using devices with different base lifetimes is presented for the on-state current-voltage characteristics, the steady-state saturation current, and the current and voltaqe waveforms for the constant voltage transient, the inductive loar transient, and the series resistor-inductor load transient.

[Contact: Allen R. Hefner, (301)

975-2071]

Hefner, A.R., Blackburn, D.L., and Galloway, K.F., A Steady-State Model for the Insulated Gate Bipolar Transistor, to be published in the Proceedings of the Fourth International workshop on Physics of semiconductor De- 
Device Physics \& Modeling (cont'd.)

vices, Madras, India, December 10-15, 1987.

The power Insulated Gate Bipolar Transistor (IGBT) is a switching device designed to overcome the high on-state loss of the power MOSFET. The IGBT behaves as a bipolar transistor which is supplied base current by a MOSFET. The bipolar transistor of the IGBT has a wide base with the base contact at the collector edge of the base and is operated with its base in high-level injection. The usual bipolar transistor models are not adequate for the IGBT. This paper describes a model for the IGBT developed using ambipolar transport.

[Contact: Allen R. Hefner, (301)

975-2071]

Gaitan, M., and Mayergoyz, I., Numerical Analysis for the Small-signal Response of the MOS Capacitor.

The small-signal sinusoidal steady-state response of the MOS capacitor is simulated by solving the basic semiconductor equations using time perturbation analysis. The effect of nonuniform doping profiles, interface traps, and bulk traps are included. The model uses Fermi-Dirac statistics and ShockleyRead-Hall recombinations to describe the traps. This analysis is an improvement over previous analytical techniques since it simulates the small-signal response of the MOS capacitor through $i$ ts whole range of operation, including the frequency-dependent inversion layer response due to the traps.

[Contact: Michael Gaitan, (301)

975-2070]

Lowney, J.R., and Kahn, A.H., ValenceBand Effective Masses of GaAs.

The density of states effective masses for the heavy-hole, light-hole, and split-off valence bands of GaAs have been calculated as a function of energy in each band. The calculations are based on the theory of Dresselhaus, Kip, and Kittel with matrix elements determined by the method of cardona. The most recent values for these matrix elements are used. Provision has been made for the effect of the split-off energy on the matrix elements of the split-off band. The results show important nonparabolicities which should be taken into account in modeling the valence band.

[Contact: Jeremiah R. Lowney, (301)

975-2048]

Recently Published

Bennett, H.S., Numerical Simulations on Neutron Effects on Bipolar Transistors, IEEE Transactions on Nuclear Science, Vol. N.S-34, No. 6, pp. 1372-1375 (1987).

A detailed device model that has been verified by comparisons with experimental measurements on unirradiated, stateof-the-art bipolar devices has been modified to include the effects of neutron radiation on carrier lifetimes, concentrations, and mobilities. Numerical experiments on the degradation due to neutron fluences in the dc common emitter gains for bipolar transistors with submicrometer emitter and base widths are given and compared in general terms with the few published measurements.

[Contact: Herbert $S$. Bennett, (301) 975-2079]

Bennett, H.S., and Lowney, J.R., Physics for Models of Gallium Arsenide Devices, Fundamental Research on the Numerical Modellina of Semiconductor Devices and Processes, J.J.H. Miller, Ed. (Boole, Dublin, 1987), pp. 31-36. [Proceedings of NuMOS 1, First International workshop on the Numerical Modelling of Semiconductors, Los Anqeles, California, December 11-12, 1986.]

Numerically simulating the behavior of GaAs devices requires a model for the distorted densities of states, band edge shifts, $\Delta E_{C}$ and $\Delta E_{V}$, and effective 
Device Physics \& Modeling (cont'd.)

intrinsic carrier concentrations, $\mathrm{n}_{i e}$. The subscripts $\mathrm{c}$ and $\mathrm{v}$ denote the conduction and valence bands, respectively. Klauder's self-energy methods (third-level and fifth-level) are applied to calculate the effects of carrier-dopant ion interactions on the densities of states for GaAs. The effects of carrier-carrier interactions have been calculated according to the theory of Abram et al. modified for 300 $K$. These calculations span most of the range of densities encountered in GaAs devices. This range is $5 \times 10^{16} \mathrm{~cm}^{-3}$ to $10^{19} \mathrm{~cm}^{-3}$ for n-type GaAs and from $10^{18}$ $\mathrm{cm}^{-3}$ to $10^{20} \mathrm{~cm}^{-3}$ for p-type GaAs. We present in this paper theoretical data on how $\Delta E_{C}, \Delta E_{v}$, and $n_{i e}$ vary with dopant densities. The variations with dopant and/or carrier densities of the distorted densities of states, Fermi energies screening radii, and first Born shifts will be given in a future publication.

[Contact: Herbert S. Bennett, (301) 975-2081]

Kim, J.S., The Effect of the Gate Oxide Thickness on the Speed of MOS Integrated Circuits, NBSIR 87-3668 (December 1987).

A simple analysis is presented for the effect of the gate oxide thickness on the circuit speed in a short-channel cmos/inverter delay circuit. The present analysis is performed within the first-order theory of the mos transistor. The result of the analysis shows that an optimum value of the gate oxide thickness exists, beyond which a further scaling of the gate oxide will not improve but degrade the circuit speed. The circuit speed corresponding to this optimum oxide thickness is the ultimate upper limit theoretically possible in a given MOS integrated circuit. The optimum value of the gate oxide thickness, to a first-order approximation, is proportional to the channel width $w$, but it is independent of the channel length L. In particular, for wide channel devices, this optimum value exceeds the $5-\mathrm{nm}$ to $30-\mathrm{nm}$ range, which is of practical significance in the design and processing of advanced VLSI circuits. At the optimum oxide thickness, the square-root of the net propagation delay is the sum of two components: the square-root of a purely parasitic component and the square-root of a device-dependent component.

[Contact: Jin S. Kim, (301) 975-2238]

Radiation Effects

Recently Published

Singh, G., Galloway, K.F., and Russell, T.J., Temperature Induced Rebound in Power MOSFETS, IEEF Transactions on Nuclear Science, Vol. NS-34, No. 6, pp. 1366-1369 (1987).

Enhancement mode n-channel power MOSFFTs were investigated for rebound. They received $300 \mathrm{krad}(\mathrm{Si})$ qamma dose under positive gate bias with source and drain grounded. The irradiated transistors were thermally annealed with all terminals shorted or under positive qate bias with drain and source shorted, at temperatures from $60^{\circ} \mathrm{C}$ to $150^{\circ} \mathrm{C}$. Threshold voltage rebound was observed for some transistor types under certain experimental conditions.

[Contact: Thomas J. Russell, (301) 975-2073]

Suehle, J.S., Russell, T.J., and Gallo way, K. F., Interface Trap Effects on the Hot-Carrier-Induced Degradation of MOSFEIs During Dynamic stress, IEFF, Transactions on ruclear Science, Vol. NS-34, No. 6, pp. 1359-1363 (1987).

Foundry and hardened n-channel MOSFFiTs were stressed with dynamic $A C$ pulses and with static DC voltages. The pre-radiation hot-carrier-induced deqradation is much more severe in the dynamic case than in the static case for the hardened devices. The data sugqest that the pre-radiation hot-carrier deqradation is strongly influenced by the relative density of interface traps and by the 
Radiation Effects (cont'd.)

pulse structure. The post-radiation hot-carrier degradation is mainly influenced by the amount of radiation-induced fixed oxide charge.

[Contact: John S. Suehle, (301)

975-2247]

Insulators and Interfaces

Recently Published

Baghdadi, A., and Walters, E.J., Semiconductor Measurement Technology: Silicon-on-Insulator: A Categorized Bibliography Including Abstracts, NBS Special Publication 400-80 (December 1987).

This bibliography of silicon-on-insulator SOI technology was compiled from a literature search of three data bases; INSPEC, Engineering Index, and Chemical Abstracts. The bibliography has been categorized according to the technique used to produce the SOI substrate. It includes the abstracts for most of the papers. It can either be used to obtain a quick evaluation of the "state of the art" in a particular soI technique, or as a guide for further in-depth study. [Contact: Aslan Baghdadi, (301)

975-2062]

Photodiodes

Recently Published

Korde, R., and Geist, J., Quantum Efficiency stability of Photodiodes, Applied Optics, Vol. 26, pp. 5284-5290 (1987).

The stability of the quantum efficiency of inversion layer, phosphorus-diffused (n-conductivity type on $\underline{p}$ ) and borondiffused ( $\underline{p}$ on $\underline{n}$ ) photodiodes has been investigated. Unsatisfactory siliconsilicon dioxide interfaces, latent recombination centers in the diffused layers, and moisture absorption by the device were identified as possible causes of instability. Diodes were fabricated using processes in which these sources of instability were carefully controlled. The resulting diodes were subjected to various accelerated aging tests, and the external quantum efficiency of the diodes was monitored during the tests. Diodes made by older procedures, in which some important parameters affecting stability were not controlled, were included in the study for comparison. The major result of this work is the demonstration that $\mathrm{n}$ on $\underline{\mathrm{p}}$ photodiodes are inherently more stable than $\underline{p}$ on $\mathrm{n}$ types in the ultraviolet and blue spectral regions, but that stable $p$ on $\mathrm{n}$ devices can also be produced with sufficient care.

[Contact: Jon Geis.t, (301) 975-2066]

Other Semiconductor Metrology Topics

Recently Published

Scace, R.I., ASTM and SEMI Standards for the semiconductor Industry, Emerging Semiconductor Technology, Vol. ASTM STP-960, D.C. Gupta and P.H. Langer, Eds., pp. 15-18 (1987).

This article, based on an introductory talk at the symposium, points out the needs for standards in the semiconductor industry and briefly describes the activities of the orqanizations that develop them. The direct cooperation between the several organizations in the world active in semiconductor standards development is briefly described. Readers are invited to join these development activities.

[Contact: Robert I. Scace, (301)

975-2220]

FAST SIGNAL ACQUISITION, PROCESSING, AND TRANSMISSION

Waveform Metrology

Released for Publication

Leedy, T.F., and Bell, B.A., Concepts for ATE Systems Calibration: Transport Standards to Achieve Traceability to National standards, to be published 


\section{Waveform Metrology (cont'd.)}

in the Proceedings of the 1988 Measurement Science Conference, Long Beach, California, January 28-29, 1988.

Technical objectives are presented for a proposed transport standard to establish direct traceability of selected lowfrequency electrical quantities between the National Bureau of Standards and a utomatic test systems including the calibration laboratories that support these automatic test systems. The transport standard would consist of precision ac and dc voltage and frequency sources and could also include more specialized measurement modules in future versions. The transport standard would allow the intercomparison of dc voltage, ac (root-mean-square) voltage, total harmonic distortion, phase, and frequency measurements made using automatic test equipment systems.

[Contact: Thomas F. Leedy, (301)

975-2410]

\section{Peterson, R.L., and Oldham, N.M.,} Josephson ac Voltmeter.

A technique for accurate measurement of ac voltages with Josephson junctions is described. Based on the counting of pulses generated by a Josephson junction, the method may be capable of precision at the ppm level for frequencies less than $100 \mathrm{kHz}$.

[Contact: Robert L. Peterson, (303)

4 97-3750]

Simpson, P.A., Fast-Pulse Generators and Detectors for Characterizing Laser Receivers at $\mathbf{1 . 0 6} \mu \mathrm{m}$, to be published in the Proceedings of SPIE - The International Society for Optical Engineering, P.O. Box 20, Bellingham, WA 98227 [conference, Los Angeles, California, January 11-15, 1988] .

A detector system is described which is capable of measuring the waveform of pulses used to calihrate laser receivers at $1.06 \mu \mathrm{m}$. The risetime of the system is $0.8 \mathrm{~ns}$. All parts of the system are available commercially. Also described is an optical impulse generator at 1.06 $\mu \mathrm{m}$ with a risetime of less than $100 \mathrm{ps}$. This impulse generator can be used to measure the impulse response of the detector system and of the laser receiver.

[Contact: Philip A. Simpson, (303) 497-3789]

Turgel, R.S., Mulrow, J.M., and Vecchia, D.F., NBS Phase Angle Calibration Services, to be published as NRS Special Publication 250-26.

The National Bureau of Standards (NBS) offers a calibration service for audiofrequency phase meters. The calihrations are based on a phase angle standard developed at NBS that generates two sinusoidal signals displaced relative to each another by a precisely known phase angle over a frequency range of $2 \mathrm{~Hz}$ to $50 \mathrm{kHz}$. The signal amplitudes are independently adjustable on each channel from $0.5 \mathrm{~V}$ to $100 \mathrm{~V}$. The angular resolution is better than $0.002^{\circ}$ at the low end of the frequency range and decreases to $0.005^{\circ}$ at the high end. The uncertainty of the phase angle between the two signals generated by the standard varies from $0.005^{\circ}$ to $0.04^{\circ}$, depending on frequency and amplitude.

Using the phase angle standard, phase meter readings are obtained at selected test points. From the calihration data, the phase meter response characteristic is determined and is compared to that of an ideal meter having a linear characteristic. If the phase meter response conforms to the linear model, a straight-line calibration curve is derived from the data and serves to calculate corrected readings. From the statistical parameters associated with the calibration curve, it is possihle to estimate the limits of offset hetween the calibrated meter and the calihration standard. By extension, the uncertainty of readings of the phase meter in the user's lahoratory can be estimated.

[Contact: Raymond S. Turgel, (301)

975-2420] 
Waveform Metrology (cont'd.)

Recently Published

Laug, O.B., A Precision Power Amplifier for Power/Energy Calibration Applications, IEEE Transactions on Instrument and Measurement, Vol. IM-36, No. 4, pp. 994-1000 (December 1987). [Proceedings of the IEEE Instrumentation and Measurement Technology Conference, Boston, Massachusetts, April 27-29, 1987, pp. 129-134.]

A precision power amplifier for use in power/energy calibration applications is described. The amplifier was primarily designed to boost the output amplitude of a digital generator to provide the nominal 120- or 240-root-mean-square (rms) voltage component of a "phantom" calibration power source. The amplifier has a fixed gain of 40 and can provide a maximum output voltage swing of $970 \mathrm{~V}$ peak-to-peak or $340-\mathrm{V}$ rms at $100-\mathrm{mA}$ rms. The bandwidth is from dc to $150 \mathrm{kHz}$, and at $60 \mathrm{~Hz}$ the observed no-load short-term amplitude and phase instabilities are \pm 5 $\mathrm{ppm}$ and $\pm 5 \mu \mathrm{rad}$, respectively. The amplifier design uses high-voltage n-channel MOSFETs in the output driver stage together with a unique circuit topology of opto-isolators between the low-level input stage and the high-level output stage.

[Contact: Owen B. Isaug, (301) 975-2412]

Nahman, N.S., Software Correction of Measured Pulse Data, Fast Electrical and Optical Measurements, Vol. 1, J.E. Thompson and L.H. Luessen, Eds. (Martinus Nijhoff, Dordrecht, 1986), pp. $351-417$.

The fundamental concern in the software correction of measured pulse waveform data is the solution of an ill-posed deconvolution problem which arises when one (or both) of the known waveforms is (are) corrupted by errors due to interference, noise, instrumentation drift, etc. The variables concerned are related to each other by the convolution integral. When one of the integrand functions is unknown while the other two functions are known, the convolution equation becomes an integral equation for the unknown waveform. Solution of an ill-posed deconvolution problem is obtained by signal processinq or filtering and at most yields an estimate for the unknown waveform. The objective of this discussion is to bring out the ideas of ill-posedness and to qive examples of applications to pulse measurement problems which require deconvolution, i.e., the removal (correction) of pulse source effects and/or measurement system effects as encountered in signal pulse waveform measurements and system impulse response measurements.

[Contact: William J. Gans, (303) 497-3538]

Oldham, N.M., Parker, M.E., Young, A., and Smith, A.G., A High-Accuracy, 10 $\mathrm{Hz}-1$ MHz Automatic AC Voltage Calibration system, IEFE Transactions on Instrument and Measurement, Vol. IM-36, No. 4, pp. 883-887 (December 1987). [Proceedings of the IFEE Instrumentation and Measurement Technology Conference, Boston, Massachusetts, April 27-29, 1987, pp. 279-281.]

An automatic system for calibrating high-accuracy ac voltmeters and calibrators is described. The system is hased on traditional coaxial thermal voltage converters to provide ac voltage measurement uncertainties of 5 to $20 \mathrm{ppm}$ in the audiofrequency range and 5 to 250 ppm over the full range from $10 \mathrm{~Hz}$ to 1 $\mathrm{MHz}$ at voltages between 0.5 to $600 \mathrm{~V}$. Lower levels $(0.01$ to $0.5 \mathrm{~V})$ are realized using wideband inductive dividers. Specialized hardware and measurement techniques make it possible to achieve these uncertainties in test periods of approximately $1 \mathrm{~min}$. Random errors introduced by the measurement system are typically less than 2 ppm (one standard deviation).

[Contact: N. Michael Oldham, (301) 975-2408]

Souders, T.M., Schoenwetter, H.K., and 
Waveform Metrology (cont'd.)

Hetrick, P.S., Characterization of a Sampling Voltage Tracker for Measuring Fast, Repetitive Signals, IEEE Transactions on Instrumentation and Measurement, Vol. IM-36, No. 4, pp. 956-960 (December 1987). [Proceedings of the IEEE Instrumentation and Measurement Technology Conference, Boston, Massachusetts, April 27-29, 1987, pp. 240243.]

An equivalent-time sampling and digitizing system is described, together with test methods for characterizing its dynamic performance. Time-base errors, linearity errors, step response parameters, harmonic distortion, and frequency response are considered, and typical measurement results are included. The system is capable of state-of-the-art measurements for signal frequencies up to $200 \mathrm{MHz}$.

[Contact: T. Michael Souders, (301)

975-2406]

Stenbakken, G.N., Characterizing Square and Triangular Waveforms, IEEE Transactions on Instrumentation and Measurement, Vol. IM-36, No. 4, pp. 961-963 (December 1987). [Proceedings of the IEEE Instrumentation and Measurement Technology Conference, Boston, Massachusetts, April 27-29, 1987, pp. 9-11.]

A method has been developed for determining the parameters and errors of square and triangular waveforms relative to idealized waveforms, even when the waveforms are highly distorted. The method is based on measurements obtained by sampling the waveform. An idealized waveform is fitted to these sampled data using a least-squared error algorithm. The errors in the waveform are defined as the deviations between the data samples and the ideal waveform. Also, the parameters of the measured waveform are defined as the corresponding parameters of the fitted ideal waveform.

[Contact: Gerard N. Stenbakken, (301)

975-2440]
Turgel, R.S., and Vecchia, D.F., Precision Calibration of Phase Meters, IEFE Transactions on Instrumentation \& Measurement, Vol. IM-36, No. 4, pp. 918-922 (December 1987). [Proceedings of the IEEF Instrumentation and Measurement Technology Conference, Boston, Massachusetts, April 27-29, 1987, pp. 135-137.]

Using the calibration of a phase meter with a nominally linear response as an example, a statistical approach is discussed for predicting worst-case offsets of the meter response characteristic from the value of the reference standard. A linear calibration curve is used to model the meter response, and statistical tests are described which test the appropriateness of the model and whether the calculated calibration curve differs significantly from the ideal. Various levels of corrections to he applied can then be determined on the basis of these tests, and limits to offsets are calculated for each of the levels. By extending this approach, it is possible to predict limits of uncertainty when using the calibrated meter to make measurements.

[Contact: Raymond S. Turgel, (301)

975-2420]

\section{Cryoelectronic Metrology}

Released for Puhlication

Lloyd, F.L., Hamilton, C.A., and Kao, C., A 10 V Josephson Voltage Standard.

In the last several years, large arrays of 2000 or more Josephson junctions have been used in many laboratories to generate reference voltages on the order of $1 \mathrm{~V}$. These devices can be used to calibrate standard cells and other reference devices at the $1-V$ level without the use of a voltage divider. This has resulted in substantial improvements in accuracy and has greatly simplified the operation of Josephson voltaqe standards. A series array of 15,000 to 
Cryoelectronic Metrology (cont'd.)

20,000 junctions would extend the inherent simplicity and accuracy of a direct calibration to the $10-\mathrm{V}$ level commonly used in precision zener-diode reference standards. The first observation of Josephson steps at the 10-V level used an array of 14,184 junctions. The stability and large microwave power requirements of this array made its use as a practical standard marginal. This paper describes an array with a modified design which resolves the problems of stability and power requirement. A number of the new arrays have been successfully fabricated and more than 50 calibrations have been performed at the $10-\mathrm{V}$ level.

[Contact: Frances L. Lloyd, (303) 497-3254 or 3988]

Peterson, R.L., and Oldham, N.M., Josephson ac Voltmeter.

A technique for accurate measurement of ac voltages with Josephson junctions is described. Based on the counting of pulses generated by a Josephson junction, the method may be capable of precision at the ppm level for frequencies less than $100 \mathrm{kHz}$.

[Contact: Robert L. Peterson, (303) 497-3750]

Xizhi, L., Richards, R.L., and Lloyd, F.L., SIS Quasiparticle Mixers with Bow-Tie Antennas.

We have designed and evaluated planar lithographed $\mathrm{W}$-band superconductor-insulator-superconductor mixers with bow-tie antennas and several different radio frequency coupling structures. Both $\mathrm{Pb}-\mathrm{alloy}$ and $\mathrm{Nb}-\mathrm{Pb}-\mathrm{alloy}$ junctions were used, each with $\omega \mathrm{R}_{N} \mathrm{C} \gg 1$. Single junctions and series arrays of five junctions directly attached to bow-tie antennas with no additional coupling structure gave poor performance, as expected. Single junctions with inductive microstrips and five-junction arrays with parallel wire inductors gave good coupling over bandwidths of $\simeq 5$ and
25 percent, respectively . Good aqreement is found between design calculations based on a simple equivalent circuit and measurements of the frequency dependence of the mixer gain. When good coupling was achieved, typical values of mixer gain $G_{M}(D S B) \simeq 0 \mathrm{~dB}$, noise $\mathrm{T}_{\mathrm{M}}(\mathrm{DSB}) \simeq 150 \mathrm{~K}$, and receiver noise $\simeq 200 \mathrm{~K}$ were observed. These measurements are referred to the cryostat window. When corrected for the estimater loss between the cryostat window and the antenna terminals, these values of qain are comparable to those observed for $\mathrm{w}$-band waveguide mixers with immediatefrequency matching, but the noise is significantly higher. There is evidence that the $\sim 100 \mathrm{~K}$ radiation from the heat shield surrounding the mixer reduces the gain and increases the noise. No systematic difference is observed between the performance of $\mathrm{Pb}$ (InAu)- $\mathrm{Pb}$ ( $\mathrm{Bi}$ ) junctions and $\mathrm{Nb}-\mathrm{Pb}$ (InAu) junctions when the area of the latter is a factor of three smaller and the current density is a factor of three larger to maintain the same capacitance and resistance.

[Contact: Frances L. Lloyd, (303) 497-3254]

Recently Published

Kautz, R.L., Activation Energy for Thermally Induced Escape from a Basin of Attraction, Physics Letters A, Vol. 125, No. 6,7, pp. 315-319 (November 23, 1987).

In the limit of low temperature, the most probable path for escape from a basin of attraction is the path which minimizes the available thermal noise energy required for escape. This minimum energy is the activation eneray of escape.

[Contact: Richard L. Kautz, (303)

497-3391 or -3988]

Kautz, R.L., and Lloyd, F.L., Precision of Series-Array Josephson Voltage Standards, Appl. Phys. Lett. Vol. 51, No. 24, pp. 2043-2045 (December 1987). 
Cryoelectronic Metrology (cont'd.)

Comparison of two series-array Josephson voltage standards operated at over $1 \mathrm{~V}$ shows that they differ in voltage by less than two parts in $10^{17}$.

[Contact: Richard L. Kautz, (303)

497-3391 or -3988]

Lloyd, F.L., Hamilton, C.A., Beall, J.A., Go, D., Ono, R.H., and Harris, R.E., A Josephson Array Voltage Standard at 10 Volts, IEEE Electron Device Letters, Vol. EDL-8, No. 10, pp. 449-450 (October 1987).

The technology of Josephson voltage standards has been extended to an array of 14,184 junctions which is capable of generating over 150,000 quantized voltage levels spanning the range from -12 to $+12 \mathrm{~V}$. This makes possible the direct calibration of $10-\mathrm{V}$ zener reference standards without the use of a voltage divider.

[Contact: Frances L. Lloyd, (303) 497-3254/3988]

\section{Antenna Metrology}

Released for Publication

Lewis, R.L., and Newell, A.C., An Efficient and Accurate Method for Calculating and Representing Power Density in the Near Zone of Microwave Antennas.

An efficient and reliable method has been developed for computing and exhihiting Fresnel-region fields radiated by microwave antennas using plane-wave scattering-matrix analysis. That is, we calculate near fields by numerically integrating the complex far-field antenna pattern. The predicted near fields are exhibited as relative power-density contours lying in a longitudinal plane bisecting the antenna's aperture. With spatial-coordinate scaling, each set of contours becomes a function of the relative aperture distribution and the electrical size of the antenna. If the latter is much larger than any normalized transverse coordinate of interest, the contour set becomes invariant with respect to antenna size. Thus, coordi- nate normalization can produce contours applicable to any antenna with the same relative aperture distribution, reqardless of antenna size.

The crux of the analysis consists of. handling a numerical instability which arises from integrating discrete data. A criterion is developed for excluding highly oscillatory regions of the integrand. In turn, this leads to restrictions on the output range over which the near-field computations are considered valid. With the numerical instahility problem resolved, the fast Fourier transform is used for efficient numerical integration. The predicted near fields have been compared against both measured and theoretical data, confirming that our near-field computation algorithm is capable of extremely high accuracy.

[Contact: Richard L. Lewis, (303)

497-5196]

Newell, A.C., Development of NearField Test Procedures for Communication Satellite Antennas, to he publisher as NBSIR 87-3081.

Near-field planar scanning measurement techniques are developed for application to communication satellite antennas. Methods are described for determining sampling criteria, scan limits, precise beam alignment, and swept-frequency near-field data.

[Contact: Allen C. Newell, (303)

497-3743]

Newell, A.C., Error Analysis Techniques for Planar Near-Field Measurements.

The results of an extensive error analysis on antenna rear-field polanar scanning measurements are described. It provides ways for estimating the magnitude of each individual source of error and then combining them to estimate the total uncertainty in the measurement. Mathematical analysis, computer simulation, and measurement tests are all used where appropriate.

[Contact: Allen C. Newell, (303)

497-3743] 
Antenna Metrology (cont'd.)

Newell, A.C., Improved Polarization Measurements Using a Modified ThreeAntenna Technique.

An improved three-antenna measurement of polarization is described that greatly reduces the uncertainty due to phase measurement errors.

[Contact: Allen C. Newell, (303)

497-3743]

Newell, A.C., and Stubenrauch, C.E., Effect of Random Errors in Plailar Near-Field Measurement.

Expressions are developed which relate the signal-to-noise ratio in the near field to the signal-to-noise ratio in the far field for antenna near-field planar scanning. The expressions are then used to predict errors in far-field patterns obtained from near-field data. A technique is also given to measure the noise in the far-field pattern.

[Contact: Allen C. Newell, (303)

497-3743]

Newell, A.C., Ward, R., and McFarlane, E., Gain and Power Parameter Measurements Using Planar Near-Field Techniques.

Equations are developed and measurement techniques described for obtaining gain, effective radiated power, and saturating flux. density using antenna near-field planar scanning measurements. These are compared with conventional far-field techniques, and a number of parallels are evident. These give insight to the theory and help to identify the critical measurement parameters. Application of the techniques to the Intelsat VI satellite are described.

[Contact: Allen C. Newell, (303)

497-3743]

\section{Recently Published}

Francis, M.H., and Hill, D.A., Out-ofBand Response of Array Antennas, Proceedings of the 9 th Annual Meeting and Symposium of the Antenna Measurement Technique Association (AMTA), Seattle, Washington, Septemher $28-0$ ctober 2, 1987, pp. 14-19 (1987).

At the National Bureau of Standards, we have examined the out-of-band response of array antennas from both a theoretical and experimental point of view. Theory shows that the out-of-band response of an antenna depends primarily on two factors: the antenna's input impedance and its directivity. Fxperiment shows that, for most practical purposes, the out-of-band response of an antenna can be estimated from a measurement of the antenna's input reflection coefficient alone. If the reflection coefficient is low, the antenna response will be good; if the reflection coefficient is high, the antenna response will be poor.

[Contact: Michael H. Francis, (303)

497-5873]

Hill, D.A., and Francis, M.H., Out-ofBand Response of Antenna Arrays, Proceedings of the 1987 IFEE International Symposium on Flectromaqnetic Compatibility, Symposium Record, Auqust 25-27, 1987, Atlanta, Georgia, pp. 435-438. [An expanded version appeared as NBSIR 86-2037 (June 1986).]

The response of antenna arrays to outof-band frequencies has been analyzed using the effective aperture approach. An average value of effective aperture can be obtained by averaging the incidence angle and the polarization of the incident field. Far-field patterns have also been calculated by treating the array element excitations as random variables. The randomness in the element excitations causes a decrease in directivity and an increase in sidelobe level.

[Contact: David A. Hill, (303)

497-3472]

Koepke, G.H., Hill, D.A., and Ma, M.T., Analysis of an Array of Log-Periodic Dipole Antennas for Generating Test Fields, NRSIR 87-3068 (June 1987). 
Antenna Metrology (cont'd.)

[Contact: Michael H. Francis, (303) 497-5873]

Hill, D.A., and Francis, M.H., Out-ofBand Response of Antenna Arrays, Proceedings of the 1987 IEEE International Symposium on Electromagnetic Compatibility, Symposium Record, August 25-27, 1987, At lanta, Georgia, pp. 435-438. [An expanded version appeared as NBSIR 86-2037 (June 1986).]

The response of antenna arrays to outof-band frequencies has been analyzed using the effective aperture approach. An average value of effective aperture can be obtained by averaging the incidence angle and the polarization of the incident field. Far-field patterns have also been calculated by treating the array element excitations as random variables. The randomness in the element excitations causes a decrease in directivity and an increase in sidelobe level.

[Contact: David A. Hill, (303)

497-3472]

Koepke, G.H., Hill, D.A., and Ma, M.T., Analysis of an Array of Log-Periodic Dipole Antennas for Generating Test Fields, NBSIR 87-3068 (June 1987).

An analysis of log-periodic dipole antennas was extended to study their use in arrays designed for electromagnetic susceptibility measurements. Parameters of an array of five log-periodic dipole antennas were calculated and in some cases compared to a single log-periodic dipole antenna. These parameters were used to evaluate the tradeoffs that exist in the design of an optimum transmitting antenna for susceptibility measurements.

[Contact: Galen H. Koepke, (303) 497-5766]

Muth, L.A., Experimental study of Interpanel Interactions at $3.3 \mathrm{GHz}$, Proceedings of the 9 th Annual Meeting and Symposium of the Antenna Measure- ment Technique Association (AMTA), Seattle, Washington, september $28-0$ ctober 2, 1987, pp. 25-29 (1987).

A general theoretical approach is formulated to describe the complex electromagnetic environment of an $N$-element array. The theory reveals the elementto-element interactions and multiple reflections within the array. To experimentally verify some features of the theory, measurements on experimental array panels in various confiqurations were made. These array panels consisted of 256 microstrip radiating elements. In each of the confiqurations, both the near-field and portside siqnals were measured to study the interactions between these panels. In particular, the effects of open-circuited array panels on the radiation pattern of a single panel are observed both in the near field and in the far field. It is found that internal scattering is the main mechanism of interaction between panels, rather than reradiation of sianals received from adjacent panels. The effects of scattering are observable at the $-50 \mathrm{~dB}$ level.

[Contact: Lorant A. Muth, (303) 497-3603]

\section{Laser Metrology}

Released for Publication

Scott, T.R., NBS Standards for Optical Power Meter Calibration, to be published in the DOD/ANSI/EIA Fiher optic Standardization Proceedings Pook, Arlington, Virginia, December 10-17, 1987.

The measurement of optical power in the microwatt to milliwatt power range at the National Bureau of standards is based upon a standard reference laser calorimeter called the C-Series calorimeter. The C-Series calorimeter, which is used as a national standard for the measurement of laser power/energy, was designed to he rugged, easy to use, and capable of measuring a wide range of laser wavelengths. This standard calo- 
Laser Metrology (cont'd.)

rimeter, in conjunction with various laser sources and a calibrated beamsplitter measurement system, is used to calibrate transfer standards which are, in turn, used to calibrate other optical power meters. This paper reviews the operation and capabilities of this standard calorimeter and associated measurement system and summarizes the uncertainties associated with these energy calibration measurements.

[Contact: Thomas R. Scott, (303)

497-3651]

\section{Noise Metrology}

Recently Published

Daywitt, W.C., Horn Design Equations for the NBS Horn-Type Noise Standards, NBSIR 87-3073 (August 1987).

Equations are given for calculating the interior dimensions of the horn pickup in the NBS millimeter-wave noise standards. These dimensions ensure negligible internal horn reflections, resulting in an accurate calculation of the horn attenuation. Measurements in the WR10 horn show a reflection of magnitude less than 0.001 .

[Contact: william C. Daywitt, (303)

497-3720]

Microwave and Millimeter-Wave Metrology

Recently Published

Clague, F.R., and Larsen, N.T., A

Transient Response Error in Microwave Power Meters Using Thermistor Detectors, 28th ARFTG (Automatic RF Techniques Group) Conference Digest, Saint Petersburg Beach, Florida, December 4-5, 1986, pp. 79-89 (April 1987).

Broadband coaxial thermistor mounts are commonly used in automated precision microwave measurement systems such as six-port networks. To reduce the effect of temperature drift and to decrease the total measurement time, it is desirable to measure the dc bias voltage on the thermistor mount very quickly after turning the radio frequency on or off. However, investigation has revealed that a coaxial mount may take much longer to settle to a stable dc bias voltage than the thermistor element time constant or the associated power meter servo bandwidth would indicate. If the bias voltage is measured before this transient ends, the error in the calculated $r f$ power can be very large; as much as 1.4 percent has been observed. This paper describes these transients and gives measured durations and maximum error for a number of different bolometer mounts.

[Contact: Fred R. Claque, (303)

497-5778]

Daywitt, W.C., A simple Technique for Determining Joint Losses on a Coaxial Line from Swept-Frequency Reflection Data, IEEE Transactions on Instrumentation and Measurement, Vol. IM-36, No. 2, pp. 468-473 (June 1987). [Abbreviated version published in CPEM (Conference on Precision Electromaqnetic Measurements) Digest, p. 40 (June 23-27, 1986, NBS Gaithersburg, R.F. Dziuba, Fd. ) ]

A need to separate connector loss from swept-frequency automatic network analyzer measurements to check an attenuation calculation for a low-loss, coaxial line has led to a simple graphical technique for determining joint losses. Measurements show that in addition to the connector loss, it is also possible to determine joint losses around center conductor bead supports on the line itself. Preliminary results indicate that losses in the millidecibel range can be determined to a precision of a few tenths of a millidecibel or better, even though the data are obscured by considerable connector loss and calibration error. Results were checked by independent measurements and show excellent agreement.

[Contact: William C. Daywitt, (303) 497-3720]

Daywitt, w.C., A simple Technique for 
Microwave \& Millimeter-Wave (cont'd.)

Investigating Defects in Coaxial Connectors, IEEE Transactions on Microwave Theory and Techniques, Vol. MTT35, No. 4, pp. 460-464 (April 1987).

This paper describes a technique that uses swept-frequency automatic network analyzer (ANA) data for investigating electrical defects in coaxial connectors. The technique will be useful to connector and ANA manufacturers and to engineers interested in determining connector characteristics for error analyses. A simplified theory is presented and the technique illustrated by applying it to perturbations caused by the center conductor gap in a $7-\mathrm{mm}$ connector pair.

[Contact: William C. Daywitt, (303)

497-3720]

Engen, G.F., On-Line Accuracy Assessment for the Dual Six-Port ANA: Background and Theory, IEEE Transactions on Instrumentation and Measurement, Vol. IM-36, No. 2, pp. 501-506 (June 1987). [Abbreviated version published in CPEM (Conference on Precision Electrical Measurements) Digest, p. 236 (June 23-27, 1986, NBS Gaithersburg, R.F. Dziuba, Ed.)]

One of the major challenges confronting the microwave metrologist today is that of providing an accuracy assessment for the automatic network analyzer (ANA). This paper provides the background and theory for the recently developed online solution now in use with the sixport systems at the National Bureau of Standards.

[Contact: Cletus A. Hoer, (303)

497-3705]

Hoer, C.A., On-Line Accuracy Assessment for the Dual Six-Port ANA: Treatment of Systematic Errors, IEEE Transactions on Instrumentation and Measurement, Vol. IM-36, No. 2, pp. 514-519 (June 1987).

Expressions are derived for calculating estimates of the systematic errors in dual six-port or four-port measurements of reflection coefficient and scattering parameters due to imperfections in the transmission-line standard used to calibrate the system. A new mathematical model for a four-port reflectometer makes it easier to visualize and analyze these errors. In this new model, two of the three parameters needer to characterize a four-port can be determined without standards. All imperfections in the standard perturb only the third parameter which acts as an impedance transformer.

[Contact: Cletus A. Hoer, (303) 497-3705]

Hoer, C.A., Some Questions and Answers Concerning Air Lines as Impedance Standards, 29th ARFTG (Automatic RF Techniques Group) Conference niqest, Las Vegas, Nevada, June 12-13, 1987, pp. 161-173 (1987).

This paper attempts to answer a number of questions that arise when using one or more lengths of precision coaxial transmission line to calibrate a dual six-port automatic network analyzer, questions such as: How important is the quality of the test port relative to that of the line? What type connectors should the line standards have? What are the advantages of using two lines instead of one line and a through connection when test port imperfections are considered? How many lines are optimum from a quality control point of view? What should the lenqths be? The answers to these questions appear to be:

- The quality of the line is much more important than that of the test port. A perfect line will calihrate out most imperfections in the test port. An example is given where $75-\Omega$ test ports are calibrated with $50-\Omega$ lines, and then used to measure reflection coefficient relative to $50 \Omega$ with very little error.

- Greatest accuracy is achieved with line standards having male connectors.

- Two lines get rid of many test port imperfections that one line cannot. 
Microwave \& Millimeter-Wave (cont'd.)

Three lines will show up a problem if one line is bad. Five lines will identify which line is bad. Five is probably optimum.

- There may not be an optimum for the actual lengths of a set of lines, but there does appear to be an optimum difference in the lengths.

[Contact: Cletus A. Hoer, (303)

497-3705]

Hoer, C.A., and Engen, G.F., Calibrating a Dual six-Port or Four-Port for Measuring Two-Ports with Any Connectors, Proceedings of the IEEE-MTT Symposium, Baltimore, Maryland, June 2-4, 1986, pp. 665-668 (1986).

A technique is described for calibrating a dual six-port or four-port ANA so that the scattering parameters of two-port devices having any combination of connectors can be measured. The technique is a generalization of the "thrureflect-line" calibration technique in which the "thru" is replaced with a second length of precision transmission line.

[Contact: Cletus A. Hoer, (303)

497-3705]

Hoer, C.A., and Engen, G.F., On-Line Accuracy Assessment for the Dual SixPort ANA: Extension to Nonmating Connectors, IEEE Transactions on Instrumentation and Measurement, Vol. IM-36, No. 2, pp. 524-529 (June 1987). [Abbreviated version published in CPEM (Conference on Precision Electrical Measurements) Digest, pp. 241-242 (June 23-27, 1986, NBS Gaithersburg, R.F. Dziuba, Ed.)]

A technique is described for calibrating a dual six-port or four-port automatic network analyzer (ANA) so that the scattering parameters of two-port devices having any combination of connectors can be measured. The technique is a generalization of the "thru-reflectline" calibration technique in which the "thru" is replaced with a second length of precision transmission line. Expressions for errors associated with the second line are derived.

[Contact: Cletus A. Hoer, (303) 497-3705]

Judish, R.M., and Fnqen, G.F., On-Line Accuracy Assessment for the Dual SixPort ANA: Statistical Methods for Random Errors, IEFF Transactions on Instrumentation and Measurement, Vol. IM-36, No. 2, pp. 507-513 (June 1987). [Abbreviated version published in CPFM (Conference on Precision Flectrical Me asurements) Digest, p. 237 (June 23-27, 1986, NBS Gaithersbura, R.F. Dziuba, Ed.)]

A basic property of a measurement process is that repeated observations of the same quantity will not give identical results due to the presence of random errors. In order to assess the effects of random errors in our measurement process, we need to build in redundancy. This paper presents a brief summary of the statistical methods used to evaluate the random errors in dual six-port measurements of reflection coefficient and scattering parameters.

[Contact: Rohert M. Judish, (303) 497-3380]

Juroshek, J.R., On-Iine Accuracy Assessment for the Dual Six-Port ANA: Experimental Results, IFFE Transactions on Instrumentation and Measurement, Vol. IM-36, No. 2, pp. 520-523 (June 1987). [Abbreviated version published in CPEM (Conference on Precision Electrical Measurements) Diqest, p. 240 (June 23-27, 1986, NRS Gaithersburg, R.F. Dziuba, Fd.)]

When a calibration laboratory such as the National Bureau of Standards (NBS) performs a measurement for a customer, the accuracy which the laboratory attaches to its measurements is a significant part of the customer's report. In some instances, the accuracy statement may be more important to the customer than the measurement itself. Modern automated measurement systems can often 
Microwave \& Millimeter-Wave (cont'd.)

perform hundreds of measurements in a fraction of a second. However, few, if any, of these systems attempt to assess the accuracy of those measurements in a real-time or on-line basis.

The accuracy of a modern automatic network analyzer (ANA) is a function of a number of variables. Connector quality, operator technique, system hardware, and system calibration are just a few of the many parameters that affect the day-today accuracy of an automated system. This paper describes the results of the current efforts at NBS to implement on-line accuracy estimates for its dual six-port network analyzers. Results are presented showing uncertainty estimates obtained in quasi-real time during the measurement of customers' devices. [Contact: John R. Juroshek, (303) 497-5362]

\section{Juroshek, J.R., A Study Into Measure-} ments of Connector Repeatability Using Highly Reflecting Loads, IEEE 'Transactions on Microwave Theory and Techniques, Vol. MTT-35, No. 4, pp. 457-460 (April 1987).

This paper investigates the repeatability of measurements of the reflection coefficient $\Gamma$ of highly reflecting devices with changes in the RF connector joint. The changes in the connector joint are due to disconnecting and reconnecting the connector pair. It is shown that many of the measurement discrepancies observed in practice can be explained with a simple connector model. The paper shows that the sensitivity of measuring $\mathrm{RF}$ connector changes can be increased by using highly reflecting loads. The changes in $\Gamma$ due to changes in resistance or reactance can be four times greater for highly reflecting devices $(|\Gamma| \simeq 1)$ than for nonreflecting devices $(|\Gamma| \simeq 0)$. Experiments on two devices with 14-mm connectors are described in order to compare them with theory. The basic principles described in this paper should be beneficial to connector designers who need to observe small changes in connector parameters and to the work of calibration standaris designers, where small connector imperfections are a major part of their measurement uncertainty.

[Contact: John R. Turoshek, (303)

497-5362]

Saulsbery, L.F., and Adair, R.T., ANA Measurement Results on the ARFTG Traveling Experiment, 28th ARFTG (Automatic RF Techniques Group) Conference Digest, Saint Petersburg Beach, Florida, December 4-5, 1986, pp. 65-78 (April 1987).

The Automatic RF Techniques Group (ARFTG) Executive Committee has assembled two traveling measurement assessment kits. Each of these kits consists of: $\quad 1-d B, 20-d R, 40-d R$, and $60-\mathrm{d} B$ attenuators; a $50-\Omega$ termination; a 10-cm air line; 1.2-V standing-wave ratio and $2.0-V$ standind-wave ratio mismatched terminations; and a shortcircuit termination. These devices are equipped with precision 7-mm coaxial connectors. The traveling kits are being circulated among measurement lahoratories who wish to assess their ahility to measure reflection coefficient, attenuation, and phase shift from 300 $\mathrm{MHz}$ to $17 \mathrm{GHz}$. The results obtained on ten different automated measurement systems are presented.

[Contact: Cletus A. Hoer, (303) 497-3705]

\section{Optical Fiber Metrology}

Released for Publication

Danielson, B.L., Calibration and Standardization Issues for the Optical Time-Domain Reflectometer.

We review some of the issues related to the specification and assurance of optical time-domain reflectometer (OTDR) performance. These include selection of appropriate performance parameters, definition of terms, test procedures, measurement difficulties, and use of 
Optical Fiber Metrology (cont'd.)

standard reference fibers. Some recommendations are given for an OTDR calibration program.

[Contact: Bruce L. Danielson, (303) 497-5620]

Scott, T.R., NBS Standards for Optical Power Meter Calibration, to be published in the DOD/ANSI/EIA Fiber Optic Standardization Proceedings Book, Arlington, Virginia, December 10-17, 1987.

The measurement of optical power in the microwatt to milliwatt power range at the National Bureau of Standards is based upon a standard reference laser calorimeter called the C-Series calorimeter. The c-Series calorimeter, which is used as a national standard for the measurement of laser power/energy, was designed to be rugged, easy to use, and capable of measuring a wide range of laser wavelengths. This standard calorimeter, in conjunction with various laser sources and a calibrated beamsplitter measurement system, is used to calibrate transfer standards which are, in turn, used to calibrate other optical power meters. This paper reviews the operation and capabilities of this standard calorimeter and associated measurement system and summarizes the uncertainties associated with these energy calibration measurements.

[Contact: Thomas R. Scott, (303)

497-3651]

\section{Electro-Optic Metrology}

Released for Publication

Danielson, B.L., and Whittenberg, C., Interferometric Dispersion Measurements on Small Guided-Wave Structures.

We describe a method for obtaining dispersion properties of components in micro-optic systems. The technique is based on a Fourier analysis of the reflective signatures obtained from a coherence-domain reflectometer.

[Contact: Bruce L. Danielson, (303)
497-5620]

Phelan, Jr., R.J., and Craig, R.M., An Electrically Calibrated Silicon Bolometer for Low Level Optical Power and Energy Measurements, to be published in the Proceedings of SPIF - The International Society for Optical Fngineering, P.O. Box 20, Bellingham, WA 98227 [conference, Los Angeles, California, January 11-15, 1988].

A cryogenically cooled, silicon-onsapphire, electrically calibrated holometer has been desiqned and measured to have a noise equivalent power of $10^{-1}$ l watts per root Hertz. Optical power measurement accuracies of 1 percent have been demonstrated.

[Contact: Robert J. Phelan, Jr., 497-3696]

Simpson, P.A., Fast-Pulse Generators and Detectors for Characterizing Laser Receivers at $1.06 \mu \mathrm{m}$, to be published in the Proceedings of SPIE - The International Society for Optical Fnqineering, P.O. Box 20, Bellingham, WA 98227 [conference, Los Angeles, California, January 11-15, 1988].

A detector system is described which is capable of measuring the waveform of pulses used to calibrate laser receivers at $1.06 \mu \mathrm{m}$. The risetime of the system is $0.8 \mathrm{~ns}$. All parts of the system are available commercially. Also described is an optical impulse generator at 1.06 $\mu \mathrm{m}$ with a risetime of less than $100 \mathrm{~ns}$. This impulse generator can be used to measure the impulse response of the detector system and of the laser receiver.

[Contact: Philip A. Simpson; (303) 497-3789]

Recently Published

Polak-Dingels, P., Burdge, G., Lee, Chi H., Seabaugh, A.C., Brundage, R.T., Be II, M.I., and Albers, J., An Investigation of Photoconductive Picosecond Microstripline Switches on SelfImplanted Silicon on Sapphire (SOS), 
Electro-Optic Metrology (cont'd.)

Picosecond Electronics and Optoelectronics II, F.J. Leonberger, C.H. Lee, F Capasso, and H. Morkoc, Eds. (Springer-Verlag, 1987), pp. 232-236. [Conference proceedings of the 2d Topical Meeting on Picosecond Electronics and Optoelectronics, Incline Village, Nevada, January 14-16, 1987]

Silicon-on-sapphire (SOS) switches, damaged by implantation with $270-\mathrm{keV}$ Si ions at fluence levels of $10^{l 2}$ to $2 \times$ $10^{15} \mathrm{~cm}^{-2}$, have been characterized by picosecond cross-correlation, Raman, and resistivity measurements. Response times as short as 9 ps were measured for an implant dose of $10^{14}$. Raman measurements indicate amorphous silicon is not formed until the dose reaches $2 \times 10^{15}$ $\mathrm{cm}^{-2}$, but there is no further decrease in response time at the higher doses. The resistivity peaks at the same dose level at which the minimum response time is observed, and then decreases for higher dose. The mobility decreases monotonically with increasing implant dose. We find the optimum implantation condition is one that produces heavy damage in the material without fully amorphizing the silicon. Amorphization decreases the on/off ratio of the device through reduction of both dark resistance and mobility, without increasing the speed of the device.

[Contact: Michael I. Bell, (301)

975-2044]

\section{Other Fast Signal Topics}

Released for Publication

Dulcie, L.L., and Capobianco, T.E., New Standard Test Method for Eddy Current Probes, to be published in the Proceedings of the 36th Defense Conference on Nondestructive Testing, St. Louis, Missouri, October 26-29, 1987.

Recently, a draft military standard for the characterization of eddy current probes was submitted to the U.S. Army
Materials Technology Laboratory by the National Bureau of standards. We discuss the development of a standard test set and our future plans for a roundrobin study for evaluating the draft standard in a controlled study. The test set will be used to determine impedance measurement capability and consists of two parts: (1) a prototype test block set as specified hy the draft standard and (2) a specially designed and characterized probe set. A round-robin survey will be conducted to determine ease of use, repeatahility of characterization measurements, and impedance measurement precision when using the test blocks as specified in the standard.

Round-robin participants will he military nondestructive evaluation facilities that will perform impedance measurements using the standard test set. The ability to measure impedance reliably is basic to the implementation of the standard. This reliability will be determined by a statistical analysis of measurement results received from the round-robin participants.

[Contact: Laura L. Dulcie, (303) 497-5181]

Recently Published

Hill, D.A., and Cavcey, K.H., Coupling Between Two Antennas Separated by a Planar Interface, IEFE Transactions on Geoscience and Remote Sensing, Vol. GE-25, No. 4, pp. 422-431 (July 1987).

The plane-wave spectrum technique is used to analyze the coupling between a pair of antennas separated by a planar interface. Multiple reflections between the antennas or between either antenna and the interface are included in the formulation. The formulation is used for model detection of buried objects, and a low-frequency metal detector example is analyzed in detail. For a transmitting loop and a buried oblate spheroid, the plane-wave spectrum technique is shown to agree with well-known quasistatic approximations. Some experimen- 
Other Fast Signal Topics (cont'd.)

tal results from a $3-\mathrm{kHz}$ metal detector are also shown.

[Contact: David A. Hill, (303)

497-3472]

\section{ELECTRICAL SYSTEMS}

Power Systems Metrology

Released for Publication

Martzloff, F.D., Power Quality Measurements: Bringing Order Out of Chaos, to be published in the Proceedings of the Energy Technology Conference, Washington, D.C., February 17-19, 1988.

The quality of the power supplied to sensitive electronic equipment is an important issue. Quantifying this quality, however, is difficult under the present state of nonexistent or uncoordinated standards concerning two related questions: (1) what levels of power quality are required for what types of loads, and (2) what measurement techniques are required to determine reliably the level of disturbances that reduce quality. Development of standards by the consensus process and voluntary compliance, although a slow process, is a mechanism for reaching technically sound and cost-effective solutions. Several standards projects are in progress, but need industry-wide support to become the generally accepted basis for valid and useful measurements of power quality.

[Contact: Francois D. Martzloff, (301)

975-2409]

Recently Published

Kelley, E.F., and Hebner, R.E., Electro-Optic Field Measurement at a Needle Tip and Streamer Initiation in Nitrobenzene, 1986 Annual Report of the Conference on Electrical Insulation and Dielectric Phenomena, Claymont, Delaware, November 2-6, 1986, pp. 272-277 (October 1987).
Kerr-effect electro-optic observations of the impulse field are made in the vicinity of the tip of a needle-sphere electrode geometry. Distortions from the Laplacian field indicate charge injection from the tip along a narrow channel prior to streamer initiation. Charge densities estimated to be on the order of $100 \mu \mathrm{C} / \mathrm{cm}^{3}$ exist in the channel. An order of magnitude calculation suggests that sufficient energy is deposited in the channel to cause vaporization of the liquid due to joule heating. The streamer will initiate where the charge injection channel touches the electrode.

[Contact: Edward F. Kelley, (301)

975-2424]

Kelley, E.F., Nehmadi, M., Hebner, R.F., McKenny, P.J., and Forster, F.O., Simultaneous Measurement of Light Emission, Current Pulses and Growth of Prebreakdown Streamers in Hexane, Proceedings of the 1987 Conference on Electrical Insulation and Dielectric Phenomena, Gaithersbura, Maryland, October 19-22, 1987, pp. 132-137 (October 1987).

High-speed, image-converter photoqraphy is used to document the growth characteristics of prebreakdown phenomena emanating from a cathode needle in a needle-sphere electrode system placed in a liquid. The cathode streamer qrowth characteristics are compared to the pulsed nature of the current feeding the streamer and light emission from the streamer. The fact that there is a strong temporal correlation between the current and light pulses is confirmed. However, it is found that no strond correlation exists between this pulselike behavior and the growth of the prebreakdown event, and that the streamer grows rather uniformly despite the discrete nature of the current supplied. This information should contribute to the development of theoretical modeling efforts on the generation and development of prebreakdown phenomena in liquids.

[Contact: Fdward F. Kelley, (301)

975-2424] 
Power systems (cont'd.)

McKnight, R.H., Measurement of Electric Field and Ion-Related quantities, Air Ions: Physical and Biological Aspects, Chapter 3, J.M. Charry and R.I. Kavet, Eds., pp. 23-55 (CRC Press, Inc. , Boca Raton, Florida, 1987).

Measurements of various quantities to describe the electrical characteristics of the atmosphere have been made for many decades by atmospheric scientists using a variety of instruments and measurement techniques. The purpose of this chapter is to describe those techniques which have application in present-day ion-related research. Topics covered include definitions of terms; measurements of electric field, space potential, vertical current density, conductivity, net space-charge density, unipolar ion density, and ion mobility; species identification; errors associated with external electric fields and off-ground operation of instruments; and applications of measurements (23 figures, 101 literature references).

[Contact: Ronald H. McKnight, (301)

975-2431]

McKnight, R.H., Operation of an Ion Counter in the Ground Plane Under a Monopolar High-Voltage Line, Proceedings of the Twenty-Third Hanford Life Sciences Symposium, Interaction of Biological systems with static and ELF Electric and Magnetic Fields, Richland, Washington, October 2-4, 1984, pp. 1-7 (1987).

Studies have been made of the operation of an ion counter with the inlet located in the ground plane near a monopolar high-voltage line. Electric-field values at the ground plane ranged between $14.8 \mathrm{kV} / \mathrm{m}$ and $29.8 \mathrm{kV} / \mathrm{m}$, while ion current densities varied from 0.1 to $0.43 \mu \mathrm{A} / \mathrm{m}^{2}$. An observed variation in measured ion density with volumetric flow rate through the counter appears to be primarily due to losses in the duct between the ground-plane opening and the ion-counter inlet.
[Contact: Ronald H. McKnight, (301)

975-2.431]

Van Brunt, R.J., Herron, J.T., and Fenimore, C., Corona-Induced Decomposition of Dielectric Gases, Gaseous Dielectrics $V$, Proceedings of the Fifth International Symposium on Gaseous Dielectrics, Knoxville, Tennessee, May 3-7, 1987 (Pergamon Press, New York, 1987), pp. 163-173.

A three-zone model for chemical decomposition of electroneqative qases in neqative point-plane corona discharges is proposed which considers the तischarqe glow, ion-drift, and main gas volumes respectively as separate reqions of diminishing chemical activity and increasing relative size. The proposed model is shown to be useful in predicting discharge hy-product yields and the dependences of these yields on discharce current and gas mixture composition. As an example, the model is applied here to the decomposition of pressurized $S F$ containing trace levels of water vapor and is shown to yield results for oxyfluoride production that are in satisfactory agreement with ohservations. [Contact: Richard J. Van Rrunt, (301) 975-2425]

\section{Superconductors}

Released for Publication

Ekin, J.W., Larson, T.M., Bergren, N.F., Nelson, A.J., Swartzlander, A.B., Kazmerski, L.L., Panson, A.J., and Blankenship, B.A., High-T ${ }_{C}$ Superconductor/Noble-Metal Contacts with Surface Resistivities in the $10^{-10}$ $\Omega$ - $\mathrm{cm}^{2}$ Range.

Contact surface resistivities (product of contact resistance and area) in the $10^{-10} \Omega-\mathrm{cm}^{2}$ range have been obtained for both silver and gold contacts to high$\mathrm{T}_{\mathrm{C}}$ superconductors. This is a reduction by about eight orders of maqnitude from the contact resistivity of indiumsolder connections, low enough to he considered for interconnect applica- 
Superconductors

tions. The contacts were formed by sputter depositing either silver or gold at low temperatures $\left(<100^{\circ} \mathrm{C}\right)$ on a clean surface of $\mathrm{Y}_{1} \mathrm{Ba}_{2} \mathrm{Cu}_{3} \mathrm{O}_{7-\delta} \quad(\mathrm{YBCO})$ and later annealing the contacts in oxygen. Annealing temperature characteristics show that for bulk-sintered YBCO samples, there is a sharp decrease in contact resistivity after annealing silver/YBCO contacts in oxygen for $1 \mathrm{~h}$ at temperatures above $\sim 500^{\circ} \mathrm{C}$ and gold/YBCO contacts for $1 \mathrm{~h}$ above $\sim 600^{\circ} \mathrm{C}$. oxygen annealing for longer times ( $8 \mathrm{~h}$ ) did not reduce the contact resistivity of silver contacts as much as annealing for $1 \mathrm{~h}$. Auger microprobe analysis shows that indium/YBCO contacts contain a significant concentration of oxygen in the indium layer adjacent to the YBCO interface. Silver and gold contacts, on the other hand, contain almost no oxygen and have favorable interfacial chemistry with low oxygen affinity. Silver also acts as a "switchable" passivation buffer, allowing oxygen to penetrate to the YBCO interface at elevated temperatures, but protecting the YBCO surface at room temperature.

[Contact: John W. Ekin, (303) 497-5448]

Ekin, J.W., Panson, A.J., and Blankenship, B.A., Effect of Oxygen Annealing on Low-Resistivity Contacts for High-T ${ }_{C}$ Superconductors, to be published in the Proceedings of the Materials Research society Meeting, Boston, Massachusetts, November 30December 4, 1987, M.B. Brodsky, H.L. Tuller, R.C. Dynes, and K. Kitazawa, Eds., Vol. 99 (Materials Research Society, Pittsburgh, Pennsylvania).

A method for making low-resistivity contacts to $h i g h-\mathrm{T}_{\mathrm{C}}$ superconductors has been developed, consisting of depositing noble metal contact pads (silver or gold) on a clean superconductor surface at low temperatures $\left(<150^{\circ} \mathrm{C}\right)$. After annealing the silver contact pads in oxygen at intermediate temperatures $\left(\leqslant 500^{\circ} \mathrm{C}\right)$ for $1 \mathrm{~h}$, contact resistivities less than $2 \times 10^{-8} \Omega-\mathrm{cm}^{2}$ at $76 \mathrm{~K}$ are obtained, about six orders of maqnitude less than for indium-solder contacts. Before annealing, the contact resistivities are still very low, in the $10^{-6}$ to $10^{-5} \Omega-\mathrm{cm}^{2}$ range at $76 \mathrm{~K}$, which would he useful when contacts with low fabrication temperatures are required. The voltage-current characteristics of the contacts are strongly nonlinear after annealing, having a superconducting transition character. This is ascribed to the critical current of the superconducting material being exceeded at the contact interface. Fxternal connections to the contact pads have been made using both solder and thermosonic wire-bonding techniques.

[Contact: John W. Fkin, (303) 497-5448]

Ekin, J.W., Panson, A.J., and Blankenship, B.A., Method for Making LowResistivity Contacts to High-T Ceramic Superconductors at Ambient Temperatures.

A general method for making low-resistivity contacts to high- $\mathrm{T}_{\mathrm{C}}$ superconductors at ambient temperatures has been developed, which has achieved contact surface resistivities of less than 10 $\mu \Omega-\mathrm{cm}^{2}$ at $77 \mathrm{~K}$. The contacts showed consistently low resistivity and little degradation when exposed to dry air over a four-month period and when repeatedly cycling between room temperature and 77 K. The contact method consists of three parts: minimizing exposure of the superconductor surface to air before the contacts are made; etching the superconductor surface using a sputter technique; and sputter depositing a thin layer of a conductive material with a low oxygen affinity -- silver was used -- to protect the surface and to serve as a contact pad. Fxternal connections to the contact pads have been made using both solder and ribbon-bonding techniques.

[Contact: John W. Ekin, (303) 497-5448]

Peterson, R.L., and Ekin, J.W., 
Superconductors (cont'd.)

\section{Josephson Junction Model of Critical} Current in Granular $\mathrm{Y}_{1} \mathrm{Ba}_{2} \mathrm{Cu}_{3} \mathrm{O}_{7-\delta}$.

We calculate the transport critical current density in a granular superconductor in magnetic fields below about 5 $\times 10^{-3} \mathrm{~T}$. The field dependence in this region is assumed to be controlled by intragranular or intergranular Josephson junctions. Various model calculations are fit to transport critical current data on bulk $\mathrm{Y}_{1} \mathrm{Ba}_{2} \mathrm{Cu}_{3} \mathrm{O} 7-\varepsilon$ ceramic superconductors, whose average grain size is nominally $10 \mu \mathrm{m}$. The results yield an average junction cross-sectional area (thickness $x$ length) of 4 to 6 $\mu \mathrm{m}^{2}$. If the junctions are at the grain boundaries, a London penetration depth of about 200 to $300 \mathrm{~nm}$ is inferred, consistent with other estimates. We conclude that Josephson junctions at twinning boundaries, if such junctions exist, do not limit the transport critical current in these highly twinned samples.

[Contact: Robert L. Peterson, (303) 497-3750]

Recently Published

Ekin, J.W., Irregularity in Nb-Ti Filament Area and Electric Field Versus Current Characteristics, Cryogenics, Vol. 27, pp. 603-607 (November 1987).

There is a correlation between irregularity in filament area ("sausaging") and the shape of a superconductor's electric field (E) versus current (I) relationship. The shape of the E-I characteristic is quantified in terms of the resistive transition parameter, $n$, defined by $E \propto I^{n}$. Low values of $n$ less than about 20 correlate with a wide filament diameter distribution, while $n$ values over 50 correspond to a distribution more than 2.5 times smaller. It is proposed that the low-field (constant) value of $n$ be used as an index of filament quality in evaluating different superconductors for practical applica- tions. A model is also suqgested to explain this effect in terms of a locally depressed filament critical current, which forces current to transfer across the normal matrix material into neiqhboring filaments. The relationship between $\mathrm{n}$ and the statistical distribution of filament diameters may be useful in that it permits an easy method of estimating the extent of sausaging in practical multifilamentary $\mathrm{Nb}-\mathrm{Ti}$ superconductors from measurements of $n$.

[Contact: John W. Ekin, (303) 497-5448]

Fkin, J.W., Transport Critical Currents in Bulk Sintered $\mathrm{Y}_{1} \mathrm{Ba}_{2} \mathrm{Cu}_{3} \mathrm{O}_{X}$ and Possibilities for Its Enhancement, Advanced Ceramic Materials, Vol. 2, Special Is sue 3B, pp. 586-591 (1987).

Several general processing methods for increasing the critical current density, $\mathrm{J}_{\mathrm{C}}$, in bulk sintered $\mathrm{Y}_{1} \mathrm{Ba}_{2} \mathrm{Cu}_{3} \mathrm{O}_{\mathrm{X}}$ superconductor are outlined. Data indicate that the transport $J_{C}$ in bulk polycrystalline specimens is dominated by a weak-link reqion between high-J $J_{C}$ grains and that potentially much higher $J_{C}$ may be possible. Two possible causes of such a weak-link phenomenon are considered: low $\mathrm{T}_{\mathrm{C}}$ phases or impurities localized in the qrain boundary region, and anisotropy of the superconducting properties. Several methods for minimizing the weak-link effects to increase the $J_{C}$ are discussed.

[Contact: John W. Ekin, (303) 497-5448]

Ekin, J.W., Rraginski, A.I., Panson, A.J., Janocko, M.A., Capone, D.W., Zaluzec, N.J., Flandermeyer, B., delima, O.F., Hong, M., Kwo, J., and Liou, S.H., Evidence for weak Link and Anisotropy Limitations on the Transport Critical Current in Bulk Polycrystalline $\mathrm{Y}_{1} \mathrm{Ba}_{2} \mathrm{Cu}_{3} \mathrm{O}_{\mathrm{X}}$, Journal of Applied Physics, Vol. 62, No. 12, pp. 4821-4828 (15 December 1987).

Measurements of the transport criticalcurrent $\left(\mathrm{J}_{\mathrm{C}}\right)$, magnetization $\mathrm{J}_{\mathrm{C}}$, and magnetoresistance in a number of bulk 
Superconductors (cont'd.)

sintered samples of $\mathrm{Y}_{1} \mathrm{Ba}_{2} \mathrm{Cu}_{3} \mathrm{O}_{\mathrm{X}}$ from several different laboratories indicate that the transport $J_{C}$ is limited by weak-link regions between high $\mathrm{J}_{\mathrm{C}}$ regions. The weak-link $J_{C}$ has a Josephson character, decreasing by two orders of magnitude as the magnetic field is increased from 0.1 to $10 \mathrm{mT}$ at $77 \mathrm{~K}$. An examination of the grainboundary region in $\mathrm{Y}_{2} \mathrm{Ba}{ }_{2} \mathrm{Cu}_{3} \mathrm{O}_{\mathrm{X}}$ shows no observable impurities or second phases to the scale of the [001] lattice planes $(\sim 12 \AA)$. The effect of intrinsic conduction anisotropy is discussed. A current-transfer model is proposed in which weak conduction along the c-axis plays a role in limiting $J_{C}$ at grain boundaries. Orienting the grains in the powder state during processing may result in enhanced transport $\mathrm{J}_{\mathrm{C}}$ in bulk conductors.

[Contact: John W. Ekin, (303) 497-5448]

Ekin, J.W., Panson, A.J., Braginski, A.I., Janocko, M.A., Hong, M., Kwo, J., Liou, S.H., Capone, D.W., and Flandermeyer, B., Transport Critical-Current Characteristics of $\mathrm{Y}_{1} \mathrm{Ba}_{2} \mathrm{Cu}_{3} \mathrm{O}_{\mathbf{X}}$ '
Proceedings of Symposium S 1987 Spring Meeting of the Materials Research Society, Anaheim, California, April 23-24, 1987, D.U. Gubser and M. Schluter, Eds., pp. 223-226 (1987).

Voltage vs. current (V-I) characteristics were measured at magnetic fields up to $24 \mathrm{~T}$ at a temperature of $77 \mathrm{~K}$ in several $\mathrm{Y}_{1} \mathrm{Ba}{ }_{2} \mathrm{Cu}_{3} \mathrm{O}_{\mathrm{X}}$ samples fabricated at different laboratories. Critical temperatures, $\mathrm{T}_{\mathrm{C}}$, measured by resistivity were about $93 \mathrm{~K}$. All samples showed linear V-I characteristics at current levels much greater than the critical current, $I_{C}$. However, the slope was significantly less than the normal resistance at $\mathrm{T}_{\mathrm{C}}$. The slope increased with magnetic field and reached the normal resistance value only at fields greater than $24 \mathrm{~T}$. Values of the transport critical-current density $J_{C}$ near zero magnetic field were generally low and variable (about 1 to $200 \mathrm{~A} / \mathrm{cm}^{2}$ ).
The transport $\mathrm{J}_{\mathrm{C}}$ fell sharply when magnetic field was applied, decreasing by about an order of magnitude between $10^{-3} \mathrm{~T}$ and $1 \mathrm{~T}$. This leads to an effective upper critical field for transport critical currents. in $\mathrm{Y}_{1} \mathrm{Ba}_{2} \mathrm{Cu}_{3} \mathrm{O}_{\mathrm{X}}$ that is significantly less than the upper critical field defined by the field at which the resistance increases to the normal-state value. The transport $\mathrm{J}_{\mathrm{C}}$ appears to be significantly less than $\mathrm{J}_{\mathrm{C}}$ calculated from magnetization data on similar samples. These results are consistent with the transport criticalcurrent in the $\mathrm{Y}_{1} \mathrm{Ba}{ }_{2} \mathrm{Cu}_{3} \mathrm{O}_{\mathrm{X}}$ system heing dominated by a "weak-link" reqion between high-J grains.

[Contact: John W. Ekin, (303) 497-5448]

Goodrich, L.F., Pittman, F..S., and Fkin, J.W., studies of NbTi strands Extracted from Coreless Rutherford Cables, IEFE Transactions on Maqnetics, Vol. MAG-23, No. 2, pp. 1642-1645 (March 1987).

The electromechanical properties of NbTi strands extracted from coreless Rutherford cables were studied to clarify the relative effects of strand location and field angle on current degradation that occurs in cables that have been compacted into a keystone shape. Detailed critical-current measurements were made on two samples which were fabricated under controlled conditions. These are prototype cables for high-energy physics applications. Specific factors that are addressed are the nature, location, and amount of degradation. This information is intended to lead to methods for reducing the amount of critical-current degradation in cable manufacture.

[Contact: Loren F. Goodrich, (303) 497-3143]

Magnetic Materials and Measurements

Released for Publication

Fickett, F.R., Transverse Magnetoresistance of Oxygen-Free Copper, to be published in the Proceedings of the 
Magnetic Materials (cont'd.)

10 th International Conference on Magnet Technology, Boston, Massachusetts, September 17-25, 1987 .

Recent studies on the magnetoresistance of copper with residual resistance ratios (RRR) in the range 100 to 1000 using cold work and irradiation as parameters modifying RRR show a large spread in the appropriate region of the Kohler plot. This spread is much larger than that found in our earlier work on very pure copper in which we used temperature as the main variable. We report results of $4-K$ magnetoresistance measurements on a large number of samples of copper from various sources and in various states of cold work, strain, and reanneal. A new look is taken at the kohler plot as a method for predicting magnetoresistive behavior.

[Contact: Frederick R. Fickett, (303) 497-3785]

\section{ELECTROMAGNETIC INTERFERENCE}

Radiated Electromagnetic Interference

Released for Publication

Adams, J.W., Ondrejka, A.R., and Medley, H.W., A Time-Domain System for Identification of the Natural Resonant Frequencies of Aircraft Relevant to Electromagnetic Compatibility Testing, to be published as NBSIR $87-3077$.

A method of measuring the natural resonant frequencies of a structure is described. The measurement involves radiating an aircraft with an impulsive electromagnetic field and receiving the echo reflected from this aircraft. Resonances are identified by using a mathematical algorithm based on Prony's method to operate on the digitized reflected signal. The measurement system consists of special transverse electromagnetic horns, pulse generators, a time-domain system, and an implementation of Prony's algorithm. The frequen- cy range covered is 5 to $250 \mathrm{MHz}$; this range is determined by antenna and circuit characteristics.

The use of this system is shown, and measured data from several different helicopters are presented in different forms. These different forms are needed to determine which of the resonant frequencies are real and which are false. The false frequencies are byproducts of Prony's algorithm.

[Contact: John W. Adams, (303) 497-3328]

Vanzura, E., and Adams, J.W., Generating Constant Electromagnetic Fields Inside a Partially-Loaded Shielded Room.

This paper descrihes a computer-controlled feedback system that can maintain field strength levels within moderate bounds inside a partiallyloaded shielded room. These levels are relatively uniform over a larae enough volume to allow radiated immunity testing of moderate-sized objects. The frequency range depends on the characteristics of the transmit antenna; we use 50 to $200 \mathrm{MHz}$, which is usually a difficult range to cover because of limitations of other electromagnetic compatibility/suscentibility test facilities.

The measurement system consists of a computer, signal generator, amplifier, biconical antenna, and an isotropic probe system.

[Contact: Eric Vanzura, (303) 497-5752]

\section{Recently Published}

Crawford, M.L., A TEM Driven Reverberating Chamber: A Single Facility for Radiated EMS/V Testing, $10 \mathrm{kHz}-18$ GHz?, Proceedings of the 1987 International Conference on Flectromaqnetic Compatibility (EMC EXPO), San nieqo, California, May 19-21, 1987, pp. T1 1.18-T11.28. 
Radiated EMI (cont'd.)

This paper discusses the design, operation, and evaluation of a reverberating chamber, excited by a transverse electromagnetic (TEM) transmission line, for use in establishing radiated electromagnetic fields for susceptibility/vulnerability (EMS/V) testing of electronic equipment. The potential range of application is from $10 \mathrm{kHz}$ to $18 \mathrm{GHz}$. Included are brief descriptions of the facility, the operation procedures, the method for determining the test field amplitude inside the chamber, and the evaluation of the chamber's electrical parameters such as VSWR and E-field strength as a function of input power. Also presented are the E-field spatial uniformity and a summary of measurement uncertainties and conclusions derived from the test results.

[Contact: Myron L. Crawford, (303) 497-5497]

Crawford, M.L., and Bean, J.L., NSWC Reverberating Chamber-A High Power Microwave Exposure Chamber, Proceedings of the Third National High Power Microwave Technical Conference, Kirtland Air Force Base, New Mexico, December 1-5, 1986, unpaged (1987). [An expanded version appeared under the title "Electromagnetic Radiation Test Facilities Evaluation of Reverberation Chambers Located at NSWC, Dahlgren, Virginia," NBSIR 86-3051 (June 1986).]

This paper describes measurement procedures and results obtained from evaluating the reverberating chamber facility located at the Naval Surface weapons Center (NSWC), Dahlgren, Virginia. The facility was developed by the NSWC for use in measuring and analyzing the electromagnetic susceptibility/vulnerability (EMS/V) of weapon systems and the shielding effectiveness of enclosures and shielding materials. A brief description of the facility is given including the instrumentation used for performing the evaluation and calibration of the facility and for its use in performing EMS/V tests. Measurements described include the chamber's: (1) insertion loss of coupling efficiency, (2) tuner(s) effectiveness, and (3) test zone F-field uniformity and absolute amplitude calibration. Advantages and limitation for use of the reverberating chamber method are summarized along with comments on interpreting measurement results and on conclusions derived from these studies.

[Contact: Myron L. Crawford, (303) 497-5497]

Crawford, M.L., and Koepke, G.H., Performing EM Susceptibility/Vulnerability Measurements Using a Reverberation Chamber, Proceedings of the $7 \mathrm{th}$ International Symposium and Technical Fxhibition on FMC, Zurich, Switzerland, March 3-5, 1987, pp. 121-126 (1987).

This paper discusses the design, evaluation, and use of a reverberation chamber for performing electromagnetic susceptibility (EMS) measurements of electronic equipment. Included are brief descriptions of the test procedures, application advantages and limitations, some EMS test results, interpretation of test results relative to free-space test methods, and an estimate of measurement uncertainties.

[Contact: Myron L. Crawford, (303) 497-5497]

Francis, M.H., and Hill, D.A., Out-ofBand Response of Array Antennas, Proceedings of the 9 th Annual Meetina and Symposium of the Antenna Measurement Technique Association (AMTA), Seattle, washington, September $28-0$ ctober 2, 1987, pp. 14-19 (1987).

At the National Bureau of Standards, we have examined the out-of-band response of array antennas from both a theoretical and experimental point of view. Theory shows that the out-of-band response of an antenna depends primarily on two factors: the antenna's input impedance and its directivity. Fixperiment shows that, for most practical purposes, the out-of-hand response of an antenna can be estimated from a measure- 
Radiated EMI (cont'd.)

ment of the antenna's input reflection coefficient alone. If the reflection coefficient is low, the antenna response will be good; if the reflection coefficient is high, the antenna response will be poor.

[Contact: Michael H. Francis, (303) 497-5873]

Hill, D.A., and Cavcey, K.H., Coupling Between Two Antennas Separated by a Planar Interface, IEEE Transactions on Geoscience and Remote Sensing, Vol. GE-25, No. 4, pp. 422-431 (July 1987).

The plane-wave spectrum technique is used to analyze the coupling between a pair of antennas separated by a planar interface. Multiple reflections between the antennas or between either antenna and the interface are included in the formulation. The formulation is used for model detection of buried objects, and a low-frequency metal detector example is analyzed in detail. For a transmitting loop and a buried oblate spheroid, the plane-wave spectrum technique is shown to agree with well-known quasi-static approximations. Some experimental results from a $3-\mathrm{kHz}$ metal detector are also shown.

[Contact: David A. Hill, (303)

497-3472]

Hil1, D.A., and Francis, M.H., Out-ofBand Response of Antenna Arrays, Proceedings of the 1987 IEEE International Symposium on Electromagnetic Compatibility, Symposium Record, August 25-27, 1987, Atlanta, Georgia, pp. 435-438 (1987). [An expanded version appeared as NBSIR 86-2037 (June 1986).]

The response of antenna arrays to outof-band frequencies has been analyzed using the effective aperture approach. An average value of effective aperture can be obtained by averaging the incidence angle and the polarization of the incident field. Far-field patterns have also been calculated by treating the array element excitations as random variables. The randomness in the element excitations causes a decrease in directivity and an increase in sidelobe level.

[Contact: David A. Hill,

$(303)$

497-3472]

Jesch, R.L., Measurement of Shielding Effectiveness of Different Cable and Shielding Configurations by Modestirred Techniques, NBSIR 87-3076 (October 1987).

The shielding effectiveness of cable configurations having different shielding arrangements and of shielding configurations used to terminate cable shields for helicopter wiring was measured by mode-stirred techniques. The mode-stirred measurements were taken at discrete frequencies between $200 \mathrm{MHz}$ and $6 \mathrm{GHz}$. In addition, shieldina effectiveness data on the shielding confiqurations were also obtained in a transverse electromagenetic cell down to 1 $\mathrm{MHz}$ - A description of the cable and shielding configurations is given along with plots of the measured shieldind effectiveness data as a function of frequency.

[Contact: Ramon L. Jesch, (303) 497-3496]

Kanda, M., and or $r$, R.D., Near-Field Gain of a Horn and an Open-Ended Waveguide: Comparison Between Theory and Experiment, IEFE Transactions on Antennas and Propagation, Vol. AP-35, No. 1, pp. 33-40 (January 1987). [Also appeared in Symposium Digest, proceedings of the AP-S International symposium 1986, Vol. I, pp. 91-94 (June 8-13, 1986) and in the proceedings of the Fifth International conference on Filectromagnetic Compatibility, Iniversity of York, United Kingdom, September 29-October 2, 1986, pp. 137-145.]

Generating a standard electromaqnetic field requires knowledge of the qain of the transmitting antenna. The theory and supporting experimental measurements for the near-field gain of a pyramidal 
Radiated EMI (cont'd.)

horn and an open-ended waveguide (OEG) at $450 \mathrm{MHz}$ are given. The empirical near-field gain for the OEG is derived from experimental results obtained by a two-antenna method at about $2 \mathrm{GHz}$. The theoretical near-field gain for the rectangular pyramidal horn is derived from Schelkunoff's formula. Two independent near-field gain measurements of these antennas are made using a three-antenna method and a transfer-standard-probe method. The discrepancy between theoretical and experimental results is typically less than $\pm 1 \mathrm{~dB}$.

[Contact: Motohisa Kanda, (303)

497-5320]

Koepke, G.H., Hill, D.A., and Ma, M.T., Analysis of an Array of Log-Periodic Dipole Antennas for Generating Test Fields, NBSIR 87-3068 (June 1987).

An analysis of log-periodic dipole antennas was extended to study their use in arrays designed for electromagnetic susceptibility measurements. Parameters of an array of five log-periodic dipole antennas were calculated and in some cases compared to a single log-periodic dipole antenna. These parameters were used to evaluate the tradeoffs that exist in the design of an optimum transmitting antenna for susceptibility measurements.

[Contact: Galen H. Koepke, (303)

497-5766]

Ma, M.T., and Bensema, W.D., Automated TEM Cell for Measuring Unintentional EM Emissions, Proceedings of the 1987 International Conference on Electromagnetic Compatibility (EMC EXPO), San Diego, California, May 19-21, 1987, pp. T11.1-T11.12 (1987).

This paper summarizes the basic electrical properties of a transverse electromagnetic (TEM) cell, and the underlying theoretical background, based on which a TEM cell is used to measure accurately the emission of an unknown, unintentional leakage source. The theory and mea- surements have been verified by the results of a simulated example and two experiments using a spherical dipole radiator and a small loop antenna. Recent development of an automated measurement system is also discussed. [Contact: Mark T. Ma, (303) 497-3800]

Randa, J.P., and Kanda, M., A New Approach to Volumes Irradiated by Unknown Sources, IEFE Transactions on Electromagnetic Compatibility, Vol. EMC-29, No. 4, pp. 273-281 (November 1987).

We suggest an approach to the characterization of electromaqnetic environments irradiated by unknown sources. The approach is based on the numerical solution of Maxwell's equations subject to the constraints imposed by the measured values of the field at a small number of measurement points and by boundary conditions. A thorough examination of a method for the numerical solution is presented. The examples attempted demonstrate the approach but reveal deficiencies in the numerical method. Possible future directions are suggested.

[Contact: James P. Randa, (303)

497-3150]

Wilson, P.F., and Ma, M.T., Techniques for Measuring the Shielding Effectiveness of Materials, Proceedings of the 7th International Symposium and Technical Fxhibition on EMC, Zurich, Switzerland, March 3-5, 1987, pp. 547-552. [A more complete version appeared as NBS Technical Note 1095 (May 1986).]

Four methods for measuring the shielding effectiveness of materials under various conditions are considered. Coaxial transmission line holders and a timedomain system are used to simulate plane-wave shielding performance. The dual (TEM) cell and an apertured TFM cell in a reverberating chamber are used to investigate near-field shieldina capability. Both theoretical and experimental results are discussed.

[Contact: Perry F. Wilson, (303) 497-3842] 
Radiated EMI (cont'd.)

Wu, D.I., and Chang, D.C., An Investigation of a Ray-Mode Representation of the Green's Function in a Rectangular Cavity, NBS Technical Note 1312 (September 1987).

In a rectangular cavity, it is well known that a point source-excited field can be represented either in terms of summation of modes or in terms of rays produced by the equivalent image sources. Both representations involve series that are slowly convergent, so computation of fields inside the cavity is difficult. To obtain a numerically efficient scheme, a hybrid ray-mode representation is developed here using the finite poisson summation formula. The modal representation is modified in such a way that all the modes near resonance are retained while the truncated remainder of the mode series is expressed in terms of a weighted contribution of rays. For a large cavity, the contribution of rays from far away images becomes small; therefore, the ray sum can be approximated by one or two dominant terms without a loss of numerical accuracy. To illustrate the accuracy and the computational simplification of this ray-mode representation, numerical examples are included with the conventional mode series (summed at the expense of long computation time) serving as a reference.

[Contact: Doris I. Wu, (303) 497-3842]

Conducted Electromagnetic Interference

Released for Publication

Martzloff, F.D., Power Quality Measurements: Bringing Order Out of Chaos, to be published in the Proceedings of the Energy Technology Conference, washington, D.C., February $17-19,1988$.

The quality of the power supplied to sensitive electronic equipment is an important issue. Quantifying this quality, however, is difficult under the present state of nonexistent or uncoordinated standards concerning two related questions: (1) what levels of power quality are required for what types of loads, and (2) what measurement techniques are required to determine reliably the level of disturbances that reduce quality. Development of standards by the consensus process and voluntary compliance, althouqh a slow process, is a mechanism for reaching technically sound and cost-effective solutions. Several standards projects are in progress, but need industry-wide support to become the generally accepted basis for valid and useful measurements of power quality.

[Contact: Francois D. Martzloff, (301)

975-2409]

\section{ADDITIONAL INFORMATION}

Lists of Publications

Gibson, K.A., Page, J.M., and Miller, C.K.S., A Bibliography of the NBS Electromagnetic Fields Division Publications, NBSIR 85-3040 (February 1986).

This bibliography lists publications of the National Bureau of Standards' Electromagnetic Fields Division for the period from January 1984 throuqh September 1985, with selected earlier publications from the Division's predecessor organizations.

[Contact: Kathryn A. Gibson, (303)

497-3132]

Kline, K.F., and DeWeese, M.F., Metrology for Electromagnetic Technology: A Bibliography of NBS Publications, NBSIR 87-3074 (June 1987).

This bibliography lists the publications of the personnel of the Electromaqnetic Technology Division of NBS in the period from January 1970 through Decemher 1986. A few earlier references that are directly related to the present work of the Division are included.

[Contact: Sarabeth Moynihan, (303)

497-3678] 
Lists of Publications (cont'd.)

Palla, J.C., and Meiselman, B., Electrical and Electronic Metrology: A Bibliography of NBS Electrosystems Division Publications, NBS List of Publications 94 (January 1988).

This bibliography covers publications of the Electrosystems Division, Center for Electronics and Electrical Engineering, NBS, and of its predecessor sections for the period January 1963 to January 1988. A brief description of the Division's technical program is given in the introduction.

[Contact: Jenny C. Palla, (301)

975-2220]

Walters, E.J., Semiconductor Measurement Technology, NBS List of Publications 72, [a bibliography of NBS publications for the years 1962-1987] (March 1988).

This bibliography contains reports of work performed at the National Bureau of Standards in the field of Semiconductor Measurement Technology in the period from 1962 through December 1987. An index by topic area and a list of authors are provided.

[Contact: E. Jane Walters, (301)

975-2050]

\section{CEEE Calendar}

Se ptember 12-14, 1988 (San Jose, CA)

VLSI and GaAs Chip Packaging Workshop. This workshop is co-sponsored by the Components, Hybrids, and Manufacturing Technology Society of IEEE and NBS; attendees are expected to be knowledgeable in the field and to participate in discussions. Topic areas include: VLSI and wafer-scale package design (characterization and implementation, cost and performance-driven solutions); package thermal design (characteristics, results, and issues); package interconnection options (wire bonding, TAB, flip chip, or optical); GaAs IC packaging (high-speed packaging considerations); package electrical issues (reduction of parasitics, improvements in electrical performance, reduction in line resistance); integratinq package desiqn (from die to system, including assembly and test issues); VLSI package materials advancements; die-attach solutions for large chips; and new failure mechanisms in VLSI packaging. [Contact: Georqe G. Ha rman, (301) 975-2097]

Planned

Early summer (Vail, CO)

Combined Short Course on Optical Fiber and Laser Measurements. [Contact: Aaron A. Sanders, (303) 497-53411

Early fall (Boulder, CO)

Fiber Optics Symposium. [Contact: Aaron A. Sanders, (303) 497-5341]

Late fall (Boulder, Co)

Symposium on Optical Materials for High Power Lasers (20th Boulder Damaqe Symposium). [Contact: Aaron A. Sanders, (303) 497-5341]

\section{CEERE SPONSORS}

National Bureau of Standards

Department of Defense

Defense Nuclear Aqency; Defense

Advanced Research Projects

Agency; National Security Agency; Combined Army/Navy/Air Force Calibration Coordination Group

U.S. Air Force

Newark Air Force Station; Rome Air Development Center; Space \& Missile Organization; U.S. Air Force Headquarters; Wright-Patterson Air Force Base; Technical Applications Center; Kirtland Air Force Base; Cryptological Support Center

U.S. Army

Fort Belvoir; Fort Monmouth; Harry Diamond Laboratory; Materials \& Mechanics Research Center; Redstone Arsenal; 
CEEE Sponsors (cont'd.)

Strategic Defense Command; AVRADCOM (Aviation); Fort Huachuca

U.S. Navy

Naval Ocean Systems Center; Weapons Support Center/Crane; Office of Naval Research; Naval Sea Systems Command; Naval Postgraduate School; Naval Ship Research Development Center; Naval Air Systems Command; Naval Research Laboratory; Aviation Logistics Center/Patuxent; Naval Explosive ordnance

Department of Commerce

Patent and Trademark of fice
Department of Energy Energy systems Research; Fusion Fnergy; High Energy \& Nuclear Physics; Bonneville Power Administration

Department of Justice

Law Enforcement Assistance Administration

National Aeronautics and Space Administration Goddard Space Flight Center; Lewis Research Center

Nuclear Regulatory Commission. Department of Transportation National Highway Traffic Safety Administration

Sandia National Laboratories 
BIBLIOGRAPHIC DATA

SHEET (See instructions)

1. PUBLICATION OR REPORT NO.

NBSIR $88-3762$
2. Performing Organ. Report Nod 3. Publication Date

June 1988

4. TITLE AND SUBTITLE

Center for Electronics and Electrical Engineering Technical Progress Bulletin Covering Center Programs, October to December 1987 with 1988 CEEE Events Calendar

\section{AUTHOR(S)}

E. Jane Walters, compiler

6. PERFORMING ORGANIZATION (If joint or other than NBS, see instructions)

7. Contract/Grant No.

\section{NATIONAL BUREAU OF STANDARDS \\ U.S. DEPARTMENT OF COMMERCE \\ GAITHERSBURG, MD 20899}

8. Type of Report \& Period Covered

October-December 1987

9. SPONSORING ORGANIZATION NAME AND COMPLETE ADDRESS (Street, City. State, ZIP)

10. SUPPLEMENTARY NOTES

All technical information included in this document has been approved for publication previously.

$\square$ Document describes a computer program; SF-185, FIPS Software Summary, is attached.

11. ABSTRACT (A 200-word or less factual summary of most significant information. If document includes a significant bibliography or literature survey, mention it here)

This is the twenty-first issue of a quarterly publication providing information on the technical work of the National Bureau of Standards Center for Electronics and Electrical Engineering. This issue of the CEEE Technical Progress Bulletin covers the fourth quarter of calendar year 1987. Abstracts are provided by technical area for both published papers and papers approved by NBS for publication.

12. KEY WORDS (Six to twelve entries; alphabetical order; capitalize only proper names; and separate key words by semicolons) antennas; electrical engineering; electrical power; electromagnetic interference; electronics; instrumentation; laser; magnetics; microwave; optical fibers; semiconductors; superconductors

13. AVAILABILITY

Unlimited

For Official Distribution. Do Not Release to NTIS

Order From Superintendent of Documents, U.S. Government Printing Office, Washington, D.C. 20402.

[X] Order From National Technical Information Service (NTIS), Springfield, VA. 2216I
14. NO. OF PRINTED PAGES

$$
40
$$

15. Price

\section{$\$ 11.95$}


U.S. DEPARTMENT OF COMMERCE NATIONLL BUREAU OF STANDARDS

GATHEFSBURG. MO 20890

RETURN POSTAGE GUARANTEED

OFTTCLAL BUSINESS

PENALTY FOR PRIVATE USE $\$ 300$

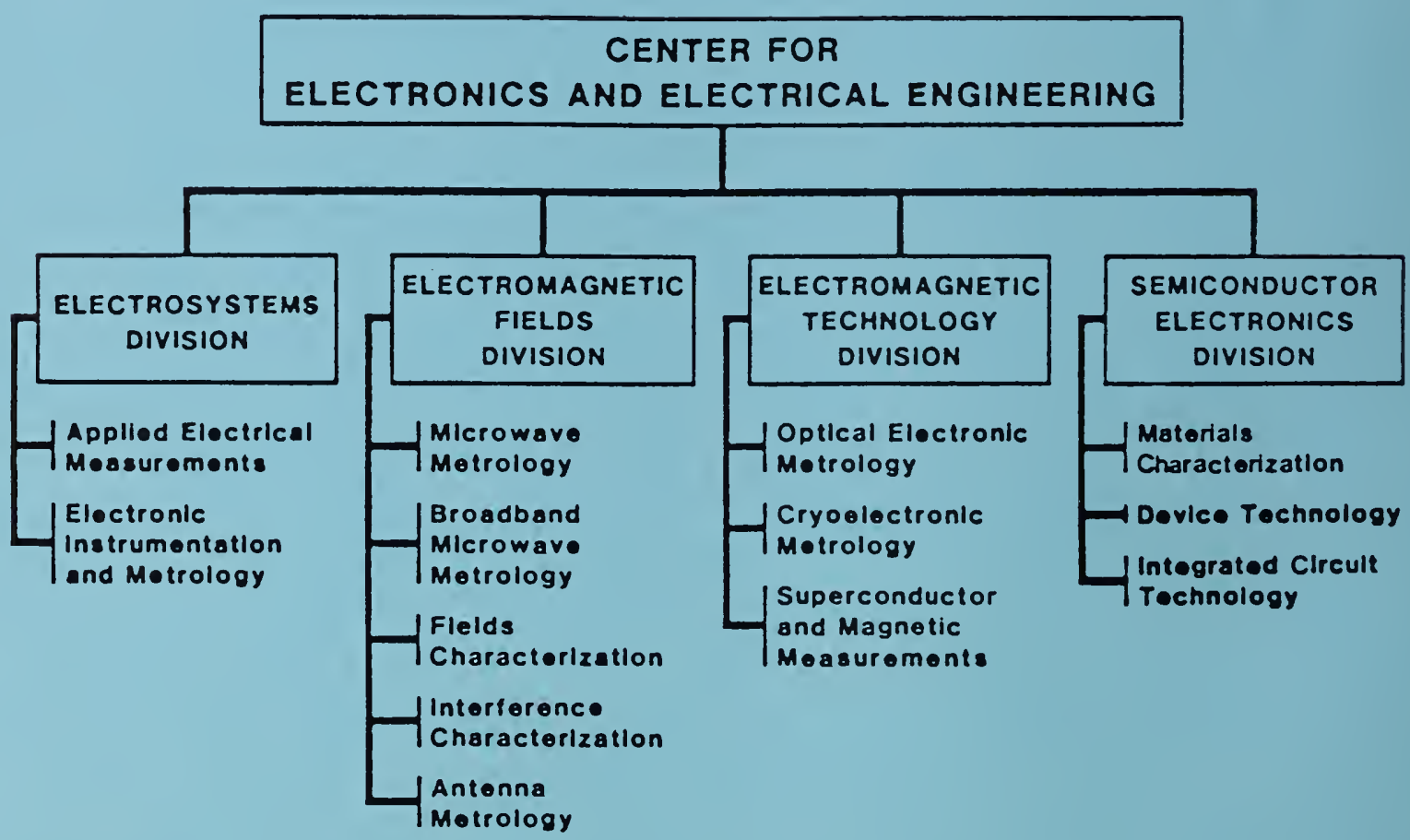

KEY CONTACTS:

Center Headquarters (720)

Electrosystems Division (722)

Electromagnetlc Flelds Division (723)

Electromagnetlc Technology DIvlsion (724)

Semiconductor Electronics Division (727)

INFORMATION:

For additional Information on the Center for Electronlcs and Electrical Engineering, write or call:
Director, Mr. Judson C. French (301) 975-2220 Deputy Director, Mr. Robert I. Scace (301) 075-2220

Chlef, Dr. Ramon C. Balrd (303) 497-3131 Chlef, Dr. Robert A. Kamper (303) 497-3535 Chlef, Mr. Frank F. Oottlnger (301) 975-2054
Chlof, Dr. Oskars Potersons (301) 975-2400

Center for Electronics and Electrical Engineering

Natlonal Bureau of Standards

Metrology Bullding, Room B-358

Galthersburg, MD 20899

Telephone (301) 975-2220 